Canadian Journal of Fisheries and Aquatic Sciences

Canadian

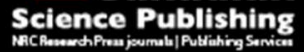

Journal canadien des sciences halieutiques et aquatiques

\title{
Development of a foraging model framework to reliably estimate daily food consumption by young fishes
}

\begin{tabular}{|r|l|}
\hline Journal: & Canadian Journal of Fisheries and Aquatic Sciences \\
\hline Manuscript ID & cjfas-2016-0331.R1 \\
\hline Manuscript Type: & Article \\
\hline Date Submitted by the Author: & $10-$ Jan-2017 \\
\hline Complete List of Authors: & $\begin{array}{l}\text { Deslauriers, David; University of Manitoba, Biological Sciences } \\
\text { Rosburg, Alex; South Dakota State University, Natural Resource } \\
\text { Management } \\
\text { Chipps, Steven; South Dakota State University }\end{array}$ \\
\hline Keyword: & $\begin{array}{l}\text { foraging ecology, sturgeon, modeling, bioenergetics, ENDANGERED } \\
\text { SPECIES < Organisms }\end{array}$ \\
\hline &
\end{tabular}

SCHOLARONE

Manuscripts 
1 Development of a foraging model framework to reliably estimate daily food

2 consumption by young fishes

4 David Deslauriers*, Alex J. Rosburg, and Steven R. Chipps ${ }^{1}$

6 Department of Natural Resource Management, South Dakota State University, SNP

7 Box 2140B, Brookings, South Dakota 57007, USA

8 Current address: Department of Biological Sciences, Room W375 Duff Roblin

9 Building, University of Manitoba, Winnipeg, Manitoba, R3T 2N2, Canada

11 1U.S. Geological Survey, South Dakota Cooperative Fish and Wildlife Research Unit,

12 Department of Natural Resource Management, South Dakota State University, SNP

13 Box 2140B, Brookings, South Dakota 57007, USA

14

$15{ }^{*}$ Corresponding author: david.deslauriers@umanitoba.ca

17 Running head: Age-0 Pallid Sturgeon Foraging Model

19 This draft manuscript is distributed solely for the purposes of scientific peer review. Its

20 content is deliberative and pre-decisional, so it must not be disclosed or released by

21 reviewers. Because the manuscript has not yet been approved for publication by the

22 U.S. Geological Survey (USGS), it does not represent any official USGS findings or policy. 


\section{Abstract}

25 We developed a foraging model for young fishes that incorporates handling and

26 digestion rate to estimate daily food consumption. Feeding trials were used to

27 quantify functional feeding response, satiation, and gut evacuation rate. Once

28 parameterized, the foraging model was then applied to evaluate effects of prey type,

29 prey density, water temperature and fish size on daily feeding rate by age-0 pallid

30 sturgeon (19-70 mm)(Scaphirhynchus albus). Prey consumption was positively

31 related to prey density (for fish $>30 \mathrm{~mm}$ ) and water temperature, but negatively

32 related to prey size and the presence of sand substrate. Model evaluation results

33 revealed good agreement between observed estimates of daily consumption and

34 those predicted by the model $\left(r^{2}=0.95\right)$. Model simulations showed that fish

35 feeding on Chironomidae or Ephemeroptera larvae were able to gain weight,

36 whereas fish feeding solely on zooplankton lost weight under most conditions. By

37 accounting for satiation and digestive processes in addition to handling time and

38 prey density, the model provides realistic estimates of daily food consumption that

39 can prove useful for evaluating rearing conditions for age-0 fishes.

40 


\section{Introduction}

Factors affecting growth and survival of fishes during their early life history

43 can have an important influence on recruitment dynamics (Madenjian and

44 Carpenter 1991; Fulford et al. 2006). Yet in natural environments, quantifying food

45 consumption for young fishes poses a challenge owing to their small size, fast

46 growth rates, and the heterogeneity of habitats in which they live in (Karjalainen et

47 al. 1996; Paradis et al. 2008). Modeling approaches provide an alternative means to

48 quantify foraging dynamics of fishes and have been particularly useful in studies of

49 larval and(or) endangered fishes (e.g., individual-based models; Winkle et al. 1997;

$50 \quad$ Nes et al. 2002; Morita and Yokota 2002; Bestgen et al. 2006).

51 The application of functional feeding models (Holling 1959) has proven

52 useful for quantifying food consumption of larval fishes in the natural environment

53 (Houde and Schekter 1980; Alanis et al. 2009; Peña-Aguado et al. 2009). Foraging

54 models of this type have been used to document predator-prey interactions that can

55 affect short (e.g., growth) and long (e.g., fitness) term population dynamics of the

56 species involved (Moustahfid et al. 2010; Hunsicker et al. 2011; Rall et al. 2012).

57 Functional feeding models pertaining to fish predators are most commonly modeled

58 as a type II functional response where intake rate declines as prey density increases

59 owing to handling time limitation of the predator (Holling 1959). The functional

60 response of predators has been shown to be species specific (Miller et al. 1992),

61 temperature dependent (Lefébure et al. 2014; Watz et al. 2014), and strongly

62 influenced by prey type and predator size (Galarowicz and Wahl 2005). Functional

63 feeding responses have been used to address a range of questions that include the 
64 impact of invasive species (Alexander et al. 2014), competitive interactions between

65 two predators (Persson 1987), and effect of refugia on prey consumption (Buckel et

66 al. 2000; Anderson 2001). Although the scaling-up of model outputs from

67 individuals to populations should be used with caution (Hunsicker et al. 2011),

68 strong inferences can be made if the functional feeding model is applied correctly

69 and the appropriate assumptions are made (Rose et al. 1999). For example, studies

70 looking to quantify functional feeding responses often rely on short-term $(<1 \mathrm{~h})$

71 feeding trials to prevent predators from becoming satiated and(or) prey from

72 becoming depleted. As a result, extrapolation of short-term feeding response to

73 estimate daily food consumption can be misleading because the effect of gut

74 residence time is usually not taken into account (Jeschke and Hohberg 2008). Thus,

75 it is often unknown if the predator is limited by its prey handling time or by the time

76 it takes to clear the gut (i.e., gut residence-time limited; Jeschke et al. 2002). An

77 additional concern pertains to the amount of time a predator can spend feeding on a

78 daily basis. This will often depend on the life stage (i.e., young fish tend to eat more)

79 and the foraging strategy of the predator (e.g., benthic vs. pelagic; visual vs.

80 sensory). For example, benthic predators such as species found in the Acipenseridae

81 family (i.e., sturgeons) rely on sensory barbels to detect prey and can thus feed

82 throughout the day and night (Taverny et al. 2002; Kynard et al. 2005; Ware et al.

83 2006) whereas visual predators (e.g., Salmonidae family) are limited by the absence

84 of daylight or increased turbidity (Mazur and Beauchamp 2003; Jönsson et al. 2013).

85 Limited reproduction associated with the endangered species status often

86 precludes efforts to study the feeding and growth of age- 0 fish in their natural 
87 environment (Hrabik et al. 2007). Thus, development of a reliable foraging and

88 growth model can provide an important tool to evaluate conditions favorable

89 towards the recovery of endangered species (Rose et al. 2013). The pallid sturgeon

90 (Scaphirhynchus albus) is a large, riverine fish endemic to the Missouri and

91 Mississippi rivers that was listed as endangered under the Endangered Species Act

92 in 1990 (Dryer and Sandvol 1993; Wildhaber et al. 2011) As a result of ongoing

93 recovery efforts, hatchery propagation programs routinely produce young pallid

94 sturgeon for stocking and research (Webb et al. 2005), providing an opportunity to

95 develop a foraging model for age-0 pallid sturgeon. Previous research has shown

96 that prey type, predator size (Rapp 2015), and water temperature (Chipps et al.

97 2009; Heironimus 2015) affect ontogenetic feeding and growth patterns of age-0

98 pallid sturgeon. In the wild, age-0 pallid sturgeon and the closely related shovelnose

99 sturgeon (Scaphirhynchus platorynchus) feed primarily on Chironomidae larvae or

100 pupae and Ephemeroptera larvae (Braaten et al. 2012; Sechler et al. 2012). Although

101 the diets of first-feeding Scaphirhyncus spp. have yet to be observed in the wild,

102 laboratory experiments have shown that while zooplankton might act as a

103 transitional food at the onset of exogenous feeding they do not represent a main

104 energy source past the initial stages of feeding (Harrison et al. 2014; Rapp 2015).

105 While diet observations are important in understanding the foraging ecology of

106 young Scaphirhynchus spp., they only provide a snapshot in time and cannot be

107 extrapolated to a daily time-scale or throughout the growing season. Understanding

108 the mechanisms that regulate prey consumption by age- 0 fishes makes it possible to

109 evaluate the impact that biotic and abiotic conditions have on energy return (Cowan 
110 et al., 2000). The ability to quantify food consumption for age-0 pallid sturgeon

111 could be used to evaluate habitat quality in the Missouri River.

112 The objective of this study was to develop a foraging model for pallid

113 sturgeon that encompasses foraging theory and physiological processes. As a basis

114 for our model, we used a framework developed for a terrestrial predator-prey

115 system that incorporates the handling and digestion of prey, where hunger level

116 (and associated feeding rate) is driven by digestive processes (Jeschke and Hohberg

117 2008). The model was designed to allow for the estimation of prey consumption

118 under different temperature, prey type, prey density, prey size, and fish size

119 conditions. Once parameterized, the model was then evaluated using a series of $24 \mathrm{~h}$

120 feeding trials across a range of age- 0 pallid sturgeon sizes, where model predictions

121 were compared to observed values of prey consumption. Finally, simulations were

122 conducted to evaluate the effect of prey type, prey density and water temperature

123 on daily energy acquisition by age- 0 sturgeon.

124

125 Materials and methods

\section{Foraging model framework}

127 The foraging model for age-0 pallid sturgeon is comprised of three main

128 components that includes (1) the functional feeding response, (2) a satiation index

129 and (3) gut residence time (Jeschke et al. 2002; Jeschke and Hohnberg 2008). The

130 first component is the functional feeding response that allows for the estimation of

131 prey handling time $\left(\mathrm{T}_{\mathrm{h}}, \mathrm{in} \mathrm{min}\right)$ and an associated attack coefficient $\left(a, \mathrm{in}^{2} / \mathrm{min}\right)$

132 based on initial prey density (no. prey $/ \mathrm{m}^{2}$ or L). Handling time $\left(\mathrm{T}_{\mathrm{h}}\right)$, in this case, 
133 incorporates the amount of time spent on the full predatory sequence, which

134 includes pursuing, capturing, and consuming a prey before resuming the search for

135 the next prey. The type II functional feeding response (Holling 1959) is represented

136 as

$137 \quad \mathrm{~N}=\frac{\mathrm{a} \cdot \mathrm{T}_{\mathrm{f}} \cdot \mathrm{x}}{\left(1+\mathrm{a} \cdot \mathrm{T}_{\mathrm{h}} \cdot \mathrm{x}\right)}$

138 where $\mathrm{N}$ is the amount of prey consumed per unit time, $a$ is the attack coefficient, $\mathrm{T}_{\mathrm{f}}$

139 is the duration of a feeding trial (i.e., $15 \mathrm{~min}$ ), $\mathrm{x}$ is prey density, and $\mathrm{T}_{\mathrm{h}}$ is handling

140 time. Using estimates of $\mathrm{N}$ from equation 1, we developed a multiple regression

141 model to predict prey consumption ( $\mathrm{N}^{\prime}$ ) as a function of pallid sturgeon length (L),

142 prey type (Prey), water temperature (Temp), and prey density (Density) as

$143 \mathrm{~N}^{\prime}=\mathrm{a}_{0}+\mathrm{a}_{1} \mathrm{~L}+\mathrm{a}_{2}$ Prey $+\mathrm{a}_{3}$ Temp $+\mathrm{a}_{4}$ Density

144 where $\mathrm{a}_{0}$ is the intercept value, and $\mathrm{a}_{1}-\mathrm{a}_{4}$ are regression coefficients. Prey

145 consumption $\left(\mathrm{N}^{\prime}\right)$ can then be integrated over time as

$146 \frac{\mathrm{dy}(\mathrm{t})}{\mathrm{dt}}=\mathrm{N}^{\prime} \cdot 4 \cdot \mathrm{h}(\mathrm{t})$

147 where $N^{\prime}$ is feeding over a 15-min interval, given by equation 2 (multiplied by 4 to

148 estimate hourly consumption), and the hunger level at time $\mathrm{t}(\mathrm{h}(\mathrm{t}))$. The hunger

149 level varies between 0 and 1 , with a value of 1 indicative of a hungry fish (i.e., empty

150 gut) and a value of 0 corresponding to a fully satiated fish. As prey are consumed

151 (given by y in equation 3) by the predator, $\mathrm{h}$ is affected as

$152 \frac{\mathrm{dh}(\mathrm{t})}{\mathrm{dt}}=\frac{1-\mathrm{h}(\mathrm{t})}{\mathrm{tg}_{\mathrm{g}}}-\mathrm{S} \cdot \mathrm{y}(\mathrm{t})$

153 where $S$ is the satiation index that specifies the proportion an individual prey item

154 constitutes of a fish's stomach fullness (see below; 2. Satiation). The gut retention 
155 time $\left(\mathrm{tg}_{\mathrm{g}}\right)$ is used to adjust $\mathrm{h}$ based on the time it takes to generate space in the gut to

156 allow for the ingestion of additional prey. Finally, prey density decreases with time

157 and can be calculated as

$158 \quad \mathrm{x}(\mathrm{t})=\mathrm{x}_{0}-\mathrm{y}(\mathrm{t})$

159 where prey density at a given time, $\mathrm{x}(\mathrm{t})$, is dependent on the initial prey density (i.e.,

160 before the beginning of the feeding trial; $\mathrm{x}_{0}$ ) and the number of prey eaten at time $t$

$161(y(t)$ given by equation 3$)$. The full foraging model consists of the coupled equations

1623 3, and 5 (Jeschke et al. 2002; Jeschke and Hohberg 2008). Depending on the prey

163 taxa, handling time or gut residence time can limit prey ingestion by predators. Once

164 fully parameterized (see methods below), the model can then be used to calculate

165 daily prey consumption by integrating the three state variables ( $\mathrm{y}, \mathrm{h}$ and $\mathrm{x}$ ) on an

166 hourly basis (24 time steps per day) using the deSolve package in R (Soetaert et al.

167 2010). It is important to mention here that 24 hour time steps were used for the

168 pallid sturgeon foraging model as preliminary experiments did not show diurnal

169 effects on consumption rate. Integration time steps of the model should be reduced

170 to accommodate species with shorter feeding periods. All statistical and modeling

171 implementations were performed using R (R Core Team 2014) and values were

172 found to be significant when $\alpha=0.05$.

173

174 Model parameterization

175 Fish Rearing

176 Larval pallid sturgeon were the progeny of captive broodstock held at the

177 U.S. Fish \& Wildlife Service Gavin's Point National Fish Hatchery (Yankton, South 
178 Dakota). Fish used in the experiments were produced in June of 2012 and 2013 and

179 came from multiple family strains. During both years, one-day post-hatch larvae

180 were transported to South Dakota State University (Brookings, South Dakota) in

181 oxygenated water ( $\sim 50$ individuals/L) from the hatchery. Upon arrival, larvae were

182 placed in $38 \mathrm{~L}$ aquaria at $16^{\circ} \mathrm{C}$ (similar as hatchery temperature) and acclimated to

18314,18 , or $24 \pm 1^{\circ} \mathrm{C}$ at a rate of $1^{\circ} \mathrm{C} / \mathrm{h}$. Fish were acclimated at these temperatures

184 for at least 5 days prior to any experimentation. Once the fish were able to feed

185 exogenously ( 18-19 mm), they were fed a mixture of dry food (70\% Otohime and

186 30\% Cyclopeeze; Kappenman et al. 2011) and thawed Chironomidae larvae. In

187 addition, live prey items (Daphnia spp., Ephemeroptera and Chironomidae larvae)

188 were fed in small quantities to the fish to avoid a naïve behavior during the feeding

189 trials that used live prey. Dry food was removed from the diet once the fish had

190 reached $30 \mathrm{~mm}$ in total length. Fish were fasted for $24 \mathrm{~h}$ prior to any trials to ensure

191 gut clearance. Fish from the same cohort (both in 2012 and 2013) were used as they

192 grew to accommodate experimentation on different size classes. Finally, fish were

193 never used more than once for any given trial.

195 1. Functional feeding response

196 We quantified the functional feeding response of pallid sturgeon larvae (19,

$19720,30,40,50$, and $70 \mathrm{~mm}$ total length) fed three prey types at water temperatures

198 of 14,18 and $24^{\circ} \mathrm{C}$. Prey types fed to pallid sturgeon included either Daphnia spp.,

199 Ephemeroptera larvae or Chironomidae larvae. Larger pallid Sturgeon (70 mm)

200 were only fed Chironomidae larvae, because previous work showed nearly exclusive 
201 feeding on this prey by fish $>50 \mathrm{~mm}$ (Rapp 2015). Feeding trials were conducted in 202 aquaria ( $900 \mathrm{~mL}$ with area of $0.095 \mathrm{~m}^{2}$ for $18-30 \mathrm{~mm}$ size classes; $2600 \mathrm{~mL}$ with 203 area of $0.0345 \mathrm{~m}^{2}$ for $40-70 \mathrm{~mm}$ size classes) that were placed in a water bath (450

204 L raceways) where water temperature was controlled using either a bayonet heater 205 (1700W; Process Technology, Mentor, OH) or a chiller unit (Frigid Units, model D120633 , Toledo, $\mathrm{OH}$ ) set to maintain target temperatures of 14,18 , or $24^{\circ} \mathrm{C}$. Small pumps 207 were placed at either end of the raceways to ensure a uniform temperature was 208 maintained. The size of the aquaria was large enough to allow fish to swim a 209 minimum of 3 body lengths in one direction regardless of fish size.

210 The range of prey densities used in the feeding trials was chosen based on

211 values reported for the Missouri River (Grohs 2009; Rapp 2015). Daphnia spp.

212 densities ranged from 15 to 90/L, whereas Chironomidae and Ephemeroptera

213 densities ranged from approximately 150 to $900 / \mathrm{m}^{2}$ (Grohs 2009). Chironomidae

214 larvae were collected in a local pond and transported to the laboratory where they

215 were sorted using 250, 500 and $750 \mu$ m sieves. Mean size of prey (length in mm)

216 used on the day a feeding trial was completed was quantified from digital pictures

$217(n=3)$ of 10 individual prey items taken from a stock tank. The invertebrates used

218 for the pictures were not used in the feeding trials. Pictures were imported into

219 Image J (Abràmoff et al. 2004), and mean prey lengths were calculated. Because

220 Chironomidae represent an important component of young pallid sturgeon diets

221 (Braaten et al. 2012; Sechler et al. 2012; Harrison et al. 2014), we conducted feeding

222 trials using four size groups of chironomids that included small $(6.07 \mathrm{~mm} \pm 1.52$

223 S.D.; $0.002 \mathrm{~g} \pm 0.001$ S.D.), medium ( $9.17 \mathrm{~mm} \pm 1.49$ S.D.; $0.005 \mathrm{~g} \pm 0.001$ S.D.), large 
224 (11.49 $\mathrm{mm} \pm 1.63$ S.D.; $0.010 \mathrm{~g} \pm 0.002$ S.D.) or mixed ( $9.38 \mathrm{~mm} \pm 2.71$ S.D.) size

225 classes. The use of different chironomid groups was intended to document size-

226 dependent capture rates by sturgeon and provide consumption estimates that were

227 representative of what would be found in the wild. No substrate (i.e., bare tank) was

228 used during these feeding trials, although in feeding trials using the "mixed" size

229 chironomids, we quantified sturgeon consumption in aquaria with or without sand

230 substrate. These additional trials were conducted because pilot studies indicated

231 that chironomids build sand casings within the first $30 \mathrm{~min}$ of being introduced to

232 the aquaria, and we hypothesized that this behavior could negatively affect the

233 foraging efficiency by pallid sturgeon. Fine silica sand (Granusil Silica) was used as a

234 substrate to facilitate the burrowing behavior of chironomid larvae and was placed

235 to cover a depth of $\sim 1 \mathrm{~cm}$ off the bottom of the containers. Trials using small,

236 medium or large size classes of Chironomidae were performed in aquaria without

237 sand substrate. In the "mixed" size group, chironomids were released into the

238 aquaria to allow them to bury if sand was present. Then, the sturgeon were placed

239 on a fine meshed screen that was installed midway through the water column of the

240 aquaria. This allowed the sturgeon to acclimate to the aquaria without having access

241 to the prey. After a 30-min period had elapsed, the screen was removed and the fish

242 could begin foraging on the prey.

243 We collected Ephemeroptera larvae (Baetidae, Ephemeridae, and

244 Heptageniidae) in a local stream using a kick net. In the laboratory, Ephemeroptera

245 larvae were carefully removed from the samples but were not sorted since the range

246 of sizes (2 to $6 \mathrm{~mm}$ ) was small. Methods for Ephemeroptera larvae feeding trials 
247 were similar to those for chironomids; however sand substrate was not used

248 because pilot studies showed that mayflies did not display a burrowing behavior.

249 Ephemeroptera larvae averaged $3.83 \mathrm{~mm} \pm 1.55$ S.D. in length and $0.006 \mathrm{~g} \pm 0.010$

250 S.D. in weight. Daphnia spp. (1.90 mm \pm 0.58 S.D.; $0.125 \mathrm{mg} \pm 0.100$ S.D.) were

251 collected in a local pond and sifted through a $2 \mathrm{~mm}$ sieve to remove large individuals

$252(>2 \mathrm{~mm})$ that exceeded the gape dimensions of the first-feeding sturgeon size-class

253 (Snyder 2002). Daphnia spp. were introduced after the sturgeon had acclimated to

254 the container.

255 Feeding trials were always performed using a single fish per aquarium and

256 were replicated five times for each combination of fish size, water temperature, prey

257 density, prey type, and(or) prey size (i.e., Chironomidae). In addition, we used a

258 total of six prey density treatments for fish $\leq 40 \mathrm{~mm}$ while five prey density

259 treatments were used for the 50 and $70 \mathrm{~mm}$ size classes. Thus, for $20 \mathrm{~mm}$ pallid

260 sturgeon maintained at $14{ }^{\circ} \mathrm{C}$, a total of 30 fish were used to evaluate predation

261 rates on Daphnia at densities of 15 to 90/L (i.e., five fish per density; Table 1).

262 Similarly, for $50 \mathrm{~mm}$ pallid sturgeon feeding at $24^{\circ} \mathrm{C}$ on small Chironomidae (180 to

263900 individuals $/ \mathrm{m}^{2}$ ), a total of 25 fish were used (Table 1). After being transferred

264 to aquaria, fish were acclimated for $30 \mathrm{~min}$ before allowed to feed for $15 \mathrm{~min}$. At the

265 end of each trial, we removed fish from the aquaria and remaining prey items were

266 counted. Consumption rates (number of prey eaten/15 min) were used to generate

267 parameter estimates for equation 1 for each feeding trial. Parameters for $\mathrm{T}_{\mathrm{h}}$ and $a$

268 were estimated using the nlsLM function in R for non-linear regression (Elzhov et al.

269 2013). Prey depletion was taken into account using the Lambert $W$ function from 
270 the emdbook package (Bolker 2013). In some cases, small pallid sturgeon $(\leq 30$

$271 \mathrm{~mm}$ ) had difficulty capturing prey items resulting in the absence of a significant

272 effect of prey density on the number of prey consumed. In these cases, the mean

273 number of prey eaten $\left(\mathrm{N}_{\mathrm{m}}\right)$ across all prey density trials was used instead of

274 estimating $\mathrm{N}$.

275 Using estimates of $\mathrm{N}$ or $\mathrm{N}_{\mathrm{m}}$, we developed a multiple regression model for

276 predicting prey consumption ( $\mathrm{N}^{\prime}$ ) as a function of pallid sturgeon size (L), prey type

277 (Prey), water temperature (Temp), and prey density (Density) (see equation 2).

278 Both $\mathrm{N}^{\prime}$ and $\mathrm{L}$ were transformed using a natural logarithmic transformation to meet

279 assumptions of normality and homogeneity of variance. Prey types (Prey) were

280 analyzed as a categorical variable and included small, medium, mixed or large

281 chironomids on bare substrate, mixed chironomids on a sandy substrate,

282 Ephemeroptera larvae, or zooplankton treatments (total of 7 prey treatments).

283 Estimates of $\mathrm{N}^{\prime}$ for each prey type were calculated by adding or subtracting their

284 parameter estimates from the intercept value based on the reference prey type (i.e.,

285 large chironomids). Because zooplankton and benthic invertebrate densities are

286 presented in different units (individuals per $\mathrm{L}$ or per $\mathrm{m}^{2}$ ), prey density (Density)

287 was expressed as a proportion of maximum prey density (i.e., maximum density =

28890 for Daphnia and 900 for Chironomidae/Ephemeroptera larvae) to explain the

289 variability associated with prey abundance. For example, a prey proportion value of

2900.5 was equivalent to 45 Daphnia/L or 450 chironomids $/ \mathrm{m}^{2}$. 
Satiation was calculated using short term (90-180 minute) feeding trials that

295 quantified the maximum amount of food a fish could eat when offered an ad-libitum

296 ration. Trials were performed using four size groups of age-0 pallid sturgeon that

297 were acclimated to $24^{\circ} \mathrm{C}$ (optimum feeding temperature; Heironimus, 2015); mean

298 length of each size group was 19 ( \pm 0.48 S.D.), 25 ( \pm 3.29 S.D.), 68 ( \pm 7.14 S.D.), or

$299122( \pm 12.66$ S.D.) $\mathrm{mm}$. The range in size groups was intended to quantify the effects

300 of fish size on satiation throughout the first growing season. Individual fish were

301 placed in $900 \mathrm{~mL}$ aquaria and allowed to acclimate for $24 \mathrm{~h}$ without being fed.

302 Following the acclimation period, smaller pallid sturgeon (19 and $25 \mathrm{~mm}$ ) were fed

30310 live Chironomidae larvae (0.001 and $0.005 \mathrm{~g}$ wet weight/chironomid) whereas

304 larger sturgeon (68 and $122 \mathrm{~mm}$ ) were fed thawed Chironomidae larvae (Hikari

305 Bio-Pure) representing 5 \% of their body weight. The smaller groups of fish (19

306 and $25 \mathrm{~mm}$ ) were allowed to feed for $30,60,90,120,150$, or 180 min while the

307 larger group of fish (68 and $122 \mathrm{~mm}$ ) were allowed to feed for $15,30,45,60,75$, or

$30890 \mathrm{~min}$. The difference in time intervals between the small and large fish groups was

309 necessary due to significantly longer handling times for smaller fish feeding on live

310 prey. A total of 5 replicates per foraging time were used for each size class of fish.

311 After each feeding trial had ended, the remaining chironomids were quantified and

312 converted to biomass. To account for the change in thawed chironomid weight that

313 might occur over time, control trials without fish ( $\mathrm{n}=5$ at each temperature) were

314 performed and prey weight loss was added to the weight of the recovered food. At 
315 the end of the trial, the fish were weighed wet (ingested food weight was

316 subtracted) and measured for total length.

317 For each pallid sturgeon size group, a one-way ANOVA was performed with

318 foraging time as the independent factor and food consumed (in g) as the dependent

319 variable. Maximum stomach fullness was identified when there was no longer a

320 significant increase in the mass of prey consumed with an increase in foraging time.

321 The mean consumption value that corresponded to stomach fullness (i.e., when the

322 fish could no longer ingest additional prey; $\mathrm{S}_{\text {Full }}$ ) was expressed as

$323 \mathrm{~S}_{\mathrm{Full}}=\mathrm{S}_{0} \mathrm{e}^{\mathrm{r} \cdot \mathrm{L}}$,

324 where $\mathrm{S}_{\text {Full }}$ is the maximum amount of food a fish can eat (in $\mathrm{g}$ ), $\mathrm{S}_{0}$ and $\mathrm{r}$ are

325 intercept and slope coefficients and $\mathrm{L}$ is fish length in $\mathrm{mm}$. The satiation index (S)

326 indicates the relative amount of a given prey that can be stored in the gut and was

327 calculated as

$328 \mathrm{~S}=1 / \mathrm{S}_{\mathrm{Full}} /$ prey $_{\mathrm{i}}$

329 where prey $y_{i}$ is the weight (g wet weight) associated with an average prey item

330 (Daphnia, Ephemeroptera larvae or chironomid). Values for S vary positively with

331 mean size of individual prey; small prey have lower S values whereas larger prey

332 have greater S values. It is assumed that all invertebrate prey items have a similar

333 specific gravity and thus a similar volume (Spaargaren 1979), implying that a fish of

334 a given size can fit the same amount of weight in its gut regardless of the prey taxon.

336

337 
Because stomach fullness in fishes can affect the functional feeding response,

340 we quantified gut residence time in pallid sturgeon as a function of body size and

341 water temperature $\left(14,18\right.$, and $\left.24^{\circ} \mathrm{C}\right)$. Trials lasted 24 hours while guts of fish were

342 examined every $4 \mathrm{~h}$. For each temperature treatment, fish were divided into groups

343 of 5 for each 4 -hour interval $(0,4,8,12,16,20$ and $24 \mathrm{~h})$ and placed individually in

$344900 \mathrm{~mL}$ aquaria. Fish (40-110 mm) were fed a known amount of thawed

345 chironomids ( 5\% Body Weight) for $30 \mathrm{~min}$ and the amount of food consumed was

346 calculated after correcting for uneaten chironomids (regurgitation was not

347 observed), which were removed following the 30 min feeding period. This

348 procedure ensured fish had a full stomach by the end of the feeding period. Fish

349 were serially sacrificed using Tricaine-S (Western Chemical inc.; [200 mg/L]) over a

$35024 \mathrm{~h}$ period (4-hour time intervals) to examine evacuation rates. The stomach was

351 cut open and food items were removed with forceps, blotted dry to remove excess

352 water, and weighed to the nearest mg. Individual fish were also weighed and

353 measured before the gut was removed. Gut residence time data followed an

354 exponential decline over time (Bochdansky \& Deibel, 2001) that could be described 355 as

$356 \quad \mathrm{~V}_{\mathrm{t}}=\mathrm{V}_{0} \mathrm{e}^{-\mathrm{rt}}$

357 where $V_{t}$ is the proportion of food left in the gut based on the amount of food

358 ingested, $\mathrm{V}_{0}$ is the intercept coefficient, $\mathrm{r}$ is the slope coefficient and $\mathrm{t}$ is the time

359 interval. A multiple regression model was constructed using the slopes (r; 
360 dependent variable) generated from the different fish size (L) and temperature

361 (Temp) combinations ( $\mathrm{N}=9 ; 3$ size categories $\mathrm{x} 3$ temperatures) as

$362 \mathrm{r}=\mathrm{a}_{0}+\mathrm{a}_{1} \mathrm{~L}+\mathrm{a}_{2} \mathrm{Temp}$,

363 where $\mathrm{a}_{0}, \mathrm{a}_{1}$ and $\mathrm{a}_{2}$ are the intercept and respective slope coefficients. The model

364 was then used to estimate $t_{\mathrm{g}}$, or the time to it takes to empty the gut as

$365 \quad t_{g}=\frac{\log (0.01)}{-r}$

367 Model evaluation

368 To evaluate the performance of the model, we conducted a series of $24 \mathrm{~h}$

369 feeding trials using a range of fish sizes (19-130 mm), Chironomidae larvae density,

370 and water temperatures $\left(14,18\right.$ and $24^{\circ} \mathrm{C}$; Table 2). Each treatment was replicated 5

371 times. Fish were allowed to acclimate to their aquaria for $24 \mathrm{~h}$ where food was not

372 provided. Prey items were introduced following the acclimation period and given 30

373 min to burrow (fish were isolated from the ground using screened mesh mid-way

374 through the water column) before fish were given $24 \mathrm{~h}$ to forage. Each aquarium

375 contained a sand substrate to allow for the chironomids to burrow. After the $24 \mathrm{~h}$

376 period, the fish were removed and measured (total length in $\mathrm{mm}$ ), and any prey not

377 consumed were quantified.

378 Observed consumption values were compared to those predicted by the

379 foraging model using linear regression analysis. To generate consumption

380 estimates, integration of equations 3, 4, and 5 was performed over 24 hours (i.e., 24

381 iterations). The hunger level was set to 1 at the beginning of the model run to

382 indicate that fish started with an empty gut. From the regression model, Bonferroni 
383 joint confidence intervals for the intercept and slope coefficients (i.e., $97.5 \%$ joint

384 confidence interval) were used to test the joint null hypothesis that the intercept

385 and slope coefficients were equal to 0 and 1 , respectively. Thus, deviation from the

386 joint null hypothesis indicates divergence between the observation and model

387 prediction. Additionally, the decomposition of mean square error (MSE) was used to

388 partition the variance into error associated with differences in the means (observed

389 and predicted), error associated with the slope differing from 1, and error linked to

390 residual variation (Rice and Cochran 1984).

391

392 Daily energy return

393 Daily maximum energy return $\left(E_{\max }\right)$ for each pallid sturgeon size group (19,

$39420,30,40$, and $50 \mathrm{~mm}$ ) was calculated as,

$395 \quad E_{\max }=y_{24} \cdot w_{i} \cdot E D_{i}$

396 where $y_{24}$ is the number of prey items consumed over a period of $24 \mathrm{~h}$ (see

397 equations 3, 4 and 5), while $\mathrm{w}_{\mathrm{i}}$ and $\mathrm{ED}_{\mathrm{i}}$ represent average weight (in g) and energy

398 density (in J/g), respectively, associated with prey $i$. Prey energy densities used

399 were 2310, 2922 or 3368 J/g for zooplankton, Chironomidae, and Ephemeroptera

400 larvae, respectively (James et al. 2012). For each prey taxon, $E_{\max }$ was calculated for

401 all prey density (proportion of maximum density used in the functional feeding

402 experiments ranging from 0 to 1; prey depletion was not allowed) and temperature

403 combinations $\left(14,18\right.$ and $\left.24^{\circ} \mathrm{C}\right) . \mathrm{E}_{\max }$ outputs were compared to the minimal

404 amount of energy required for a fish of a given size to maintain its weight over the

405 course of a day (i.e., maintenance ration). This maintenance ration (MR) provides 
406 sufficient energy for metabolic and waste processes, but does not allow for growth

407 to occur. To do so, the bioenergetics model developed by Heironimus (2015) was

408 used and can conceptually be written as

$409 \quad \mathrm{MR}=(\mathrm{R}+\mathrm{ACT}+\mathrm{SDA})+(\mathrm{F}+\mathrm{U})$

410 where MR is balanced by respiratory demands (i.e., standard metabolism (R), active

411 metabolism (ACT), and specific dynamic action (SDA)) and waste losses (i.e.,

412 egestion (F) and excretion (U)). Standard metabolism is regulated by fish weight

413 and water temperature, ACT is dependent on water temperature, while SDA, F, and

$414 \mathrm{U}$ costs are given as a proportion of energy consumed. All parameters and equations

415 for the bioenergetics model can be found in Heironimus (2015) and Deslauriers et

416 al. (2016). Because fish weight is used as input in the bioenergetics model, fish

417 length was converted to weight using the equation,

$418 \log _{10} \mathrm{~W}=\frac{\left(\log _{10} \mathrm{~L}-1.865\right)}{0.367}$,

419 where $\mathrm{W}$ is the weight of the fish $(\mathrm{g})$ and $\mathrm{L}$ is the total length ( $\mathrm{mm}$; Heironimus

420 2015). The initial weight calculated for each size class was also used as the final

421 weight value. We used a value of $2736 \mathrm{~J} / \mathrm{g}$ as input for pallid sturgeon energy

422 density (Heironimus 2015). Bioenergetics model simulations were used to generate

423 a daily maintenance ration (in Joules/d), which was subtracted from Emax $_{\operatorname{mation}}$

424 11) to calculate the net energy gain/loss of fish feeding on zooplankton,

425 Chironomidae, or Ephemeroptera larvae. 


\section{Results}

$430 \quad$ Functional feeding response

$431 \quad$ Age-0 pallid sturgeon ( $\geq 40 \mathrm{~mm}$ ) displayed a type II functional response

432 across all prey types and sizes. However, for fish $<40 \mathrm{~mm}$, most predation rates did

433 not vary with prey density, thus functional feeding coefficients were not generated.

434 As fish grew in size, capture rates for all three prey types (zooplankton,

435 Chironomidae and Ephemeroptera larvae) increased (Figure 1; see Table 3 for

436 regression coefficients). On the average, fish were able to capture more

437 Ephemeroptera larvae per unit of time, with 14\% and 19\% less zooplankton and

438 Chironomidae larvae being consumed, respectively. The presence of sand substrate

439 decreased foraging efficiency on chironomids by $86 \%$ compared to feeding off a

440 bare substrate (Figure 1; Table 3). Prey size also influenced capture rates, with large

441 (avg. $11 \mathrm{~mm}$ ) and medium (avg. $9 \mathrm{~mm}$ ) sized chironomids being captured 58\% and

$44218 \%$ less often than small chironomids (Figure 2; Table 4 and 5). As a result, the

443 maximum amount that could be ingested over a period of $15 \mathrm{~min}\left(\mathrm{~N}^{\prime}\right)$ was calculated

444 for the different prey densities and a multiple regression was generated. The model

$445\left(F_{9,1160}=425.1 ; R^{2}=0.77 ; p<0.001\right)$ indicated that fish size, water temperature, prey

446 density, prey type and the presence of sand substrate all played a significant role in

447 determining the amount of prey that could be ingested over time (Table 5).

448

449 Satiation

$450 \quad$ Foraging time did not affect consumption for the $19 \mathrm{~mm}(p=0.206), 25 \mathrm{~mm}$

$451(p=0.592)$, or $68 \mathrm{~mm}(p=0.101)$ size groups and they were thus satiated within 30 , 
45230 , or $15 \mathrm{~min}$, respectively. Foraging time was found to significantly affect

453 consumption for the larger size class of sturgeon $(122.2 \mathrm{~mm})$, that required $45 \mathrm{~min}$

454 to become fully satiated $(p=0.002)$. Stomach fullness ( $\mathrm{S}_{\mathrm{Full}}$, in $\mathrm{g}$ ) was positively

455 related to fish size $(\mathrm{L}$, in $\mathrm{mm})$ as $\mathrm{S}_{\mathrm{Full}}=0.016 \cdot \mathrm{e}^{0.027 \cdot \mathrm{L}}(\mathrm{n}=20, p<0.001)$; size-

456 dependent, stomach fullness estimates were then input into equation 7 to account

457 for weights associated with individual prey taxa (Figure 3).

\section{Gut residence time}

$460 \quad$ Gut residence time was significantly affected by water temperature and

461 followed an exponential decline over time (Figure 4). The slope coefficient (r;

462 equation 8; see materials and methods section) from each gut residence time trial

463 was used to build a multiple regression model where the slope coefficients for both

464 fish size (L) and water temperature (Temp) were found to be significant (Figure 5;

$\left.465 \quad F_{2,6}=28.5 ; R^{2}=0.87 ; p<0.001\right)$. The regression model can then be expressed as, $\mathrm{r}=0.25-0.06 \cdot \log _{\mathrm{e}}(\mathrm{L})+0.006 \cdot \mathrm{Temp}$

466 The model indicated that gut residence times were shortest for smaller fish at

467 warmer temperatures and longer for larger fish at colder temperatures (Figure 5). 468

\section{Model evaluation}

$470 \quad$ Model predictions, on average, overestimated observed food consumption

471 values by $19.6 \%$ ([1-(Predicted/Observed)]x100). Observed food consumption was

472 only slightly underestimated for the small (19 mm; $\mathrm{n}=30 ;-1.0 \%)$ and large (100

$473 \mathrm{~mm} ; \mathrm{n}=75 ;-1.1 \%$ ) size classes; however, for intermediate-sized fish (20 and $40 \mathrm{~mm}$; 
$474 \mathrm{n}=91$ ) observed food consumption values were overestimated by $47.9 \%$ and $18.4 \%$,

475 respectively (Figure 6). Regression of observed versus predicted values for all

476 feeding trials resulted in confidence intervals for the intercept and slope that

477 included 0 and 1, respectively (Table 2). MSE of observed and predicted

478 consumption values were influenced largely by the residual component (72-95\%),

479 while the mean and slope were associated with $4-20 \%$ and $1-14 \%$ of the

480 variance, respectively (Table 2). These results indicate that the model predictions

481 were able to capture relative differences between treatments and provide

482 reasonable estimates for consumption.

483

\section{Daily energy return}

485 Model simulations of daily energy consumption showed that fish could

486 maintain their weight and allocate energy towards growth when feeding on

487 Chironomidae and Ephemeroptera larvae even at low prey densities (proportion =

$4880.1)$ or water temperatures $\left(14^{\circ} \mathrm{C}\right.$; Figure 7$)$. In contrast, fish feeding on zooplankton

489 could not satisfy their daily energetic needs until they reached sizes of $40 \mathrm{~mm}$ and

490 were provided $\geq 45$ zooplankton/L (i.e., Density $=0.5$ ). Additionally, the simulations

491 demonstrated that fish smaller than $30 \mathrm{~mm}$ were limited by prey handling time

492 while larger fish were limited by their gut residence time. Lastly, energy acquisition

493 differences existing between fish feeding on Chironomidae compared to

494 Ephemeroptera decreased as fish increased in size. 


\section{Discussion}

The feeding dynamics of age- 0 pallid sturgeon were strongly influenced by

499 prey type, water temperature and sturgeon size. As reported with other fishes, age-0

500 pallid sturgeon were able to increase their search ability (i.e., attack coefficient) and

501 decrease prey handling time as they became larger (Miller et al. 1992; Galarowicz

502 and Wahl 2005; Gustafsson et al. 2010). Increases in foraging efficiency can be

503 attributed to an increase in swimming ability (Hunter 1972; Brachvogel et al. 2012),

504 a wider gape size (Wanzenböck 1995), and a larger detection span (Nunn et al.

505 2011; Watz et al. 2014). Furthermore, larger individuals are able to access a greater

506 number of prey that may be inaccessible to smaller fish (Anderson 2001), such as

507 the case building chironomid larvae. Oppositely, smaller fish with limited swimming

508 abilities might be at an advantage in laboratory feeding studies, as the area to

509 explore is much more limited than it would be in a natural setting. However, linking

510 empirical data from diet studies (Grohs et al. 2009; Braaten et al. 2012; Winders et

511 al. 2014) and prey selectivity experiments (Rapp 2015) to our modeling framework,

512 allowed us to generate reliable estimates of prey consumption under controlled

513 conditions.

514 Digestion rates and satiation indices were both important parameters in

515 regulating the amount of food consumed over the course of a day (Gill and Hart

516 1994; Munk 1995; Jeschke and Hohberg 2008). However, a sensitivity analysis of

517 the foraging model combined with a bioenergetics model (Heironimus 2015) found

518 that prey consumption estimates were more sensitive to satiation rather than

519 evacuation (Deslauriers et al. 2016). This observation does not appear to be 
520 applicable to smaller sturgeon as the ability to rapidly evacuate food at higher water

521 temperatures ensured that small sturgeon (19-30 $\mathrm{mm})$ never became satiated. As a

522 result, smaller sturgeon continuously searched for food because they were not able

523 to capture food at a rate fast enough to satiate the gut, regardless of water

524 temperature. On the other hand, modeling results showed that larger sturgeon could

525 become satiated when feeding on Chironomidae or Ephemeroptera larvae because

526 of a the combination of short handling times and slower gut evacuation rates. Only

527 when simulations involved fish feeding on zooplankton was satiation not observed,

528 even if feeding rates were high. Thus, zooplankton may not provide sufficient net

529 energy return to age- 0 pallid sturgeon, supporting related studies that show

530 generally low prey selectivity for zooplankton by age-0 sturgeon (Rapp 2015).

531 Sturgeon $<40 \mathrm{~mm}$ were found to be very inefficient predators as indicated by

532 the lack of a functional relationship for most treatments. They appeared able to

533 detect prey items but they could not capture the prey or if they did, they would

534 rapidly swim upwards and often end up losing the prey they had captured. While

535 this behavior was observed for all prey types, separate experiments provided the

536 opportunity to observe unique behaviors. For example, small zooplankton were

537 rarely captured in the water column but were captured when located at the bottom

538 of the tank, or by the pressing of the prey against the side of the tank before

539 ingesting. This behavior indicates that the capture efficiency would likely be

540 reduced in a natural setting, thus leading us to speculate that zooplankton

541 consumption provides a very negligible source of energy. Interestingly, the capture

542 efficiency of zooplankton increased with fish size indicating that larger pallid 
543 sturgeon could forage on these prey types if given no other choice. However, these

544 predators discriminate against such prey in the presence of other, more easily

545 captured prey with higher energy densities (Rapp 2015). In addition, most fish $<50$

$546 \mathrm{~mm}$ were not able to break through the sand casings built by Chironomid larvae.

547 The fish would often be able to detect a buried prey and would attack it repeatedly,

548 but would fail in capturing the prey. Ingestion thus came from chironomids that had

549 not buried, or that had been forced out of their casings by the pressure applied by

550 the sturgeon. Once the fish reached $\sim 50 \mathrm{~mm}$, they were able to create a small

551 opening in the casing and strip the prey from it. Fish $>70 \mathrm{~mm}$ were often seen

552 swallowing the prey along with its casing, and expelling sand from the mouth and

553 gill slits before ingesting the prey. Interestingly, energy return was very similar

554 across all chironomid treatments, indicating that the fish are able to compensate

555 high handling times with higher energy returns. Pallid sturgeon $<50 \mathrm{~mm}$, however,

556 were not able to capture a significantly larger amount of Chironomidae larvae

557 compared to Ephemeroptera larvae despite greater mobility associated with the

558 latter prey type. This result might have differed if trials had been performed under

559 varied water velocities, in larger foraging arenas, or by using different substrata (e.g.

560 gravel, cobble, vegetation) where Ephemeroptera larvae would have been more

561 likely to cling to the substrate or escape. Based on daily energy estimates, larger fish

562 would be able to gain about twice the energy feeding on mayflies while spending the

563 same amount of time foraging on Chironomidae larvae. This result agrees with

564 empirical diet data from pallid sturgeon captured in the Missouri River, where the 
565 fraction of Ephemeroptera larvae in guts has been shown to increase with fish size

566 (Grohs et al. 2009).

567 Optimal foraging theory predicts that predators will seek to minimize prey

568 handling time while maximizing energy return associated with available prey items

569 (Pyke 2003). By extension, age-0 pallid sturgeon would likely benefit from foraging

570 on Ephemeroptera larvae. However, when faced with the choice between

571 Chironomidae and Ephemeroptera larvae, age-0 pallid sturgeon will almost

572 exclusively select chironomids (Rapp 2015), indicating that prey selection might not

573 always be dictated by energy return (Marcotte and Browman 1985). One of the

574 problems associated with calculating energy returns in this case is that it does not

575 take fish activity levels into consideration (Giacomini et al. 2013). It is very likely

576 that age-0 sturgeon spend more energy (e.g., swimming) trying to capture

577 Ephemeroptera larvae than they would for Chironomoidae larvae, thus negating the

578 higher energy contribution of mayflies. In turn, activity levels would be expected to

579 decrease as the fish get larger, thus rendering Ephemeroptera larvae an appealing

580 prey for juvenile pallid sturgeon prior to switching to piscivory (Sherwood et al.

581 2002; Grohs et al. 2009).

$582 \quad$ As with all models, a thorough evaluation process requires confronting

583 model output with independent data before it can be applied to test hypotheses

584 (Hilborn 1997). In the current study, the evaluation process focused on the ability of

585 age-0 pallid sturgeon to forage on Chironomidae larvae since it has been shown that

586 these taxa are highly preferred in a riverine setting. The model slightly

587 overestimates consumption at higher prey densities for the intermediary size 
588 classes (i.e., 20 and $40 \mathrm{~mm}$ ), mirroring results that have employed this modeling

589 strategy in the past (Jeschke and Hohberg 2008). Reasons for overestimation might

590 be attributed to an accumulation of indigestible components (e.g., sand, chitinous

591 body parts) in the gut of the fish resulting in a higher degree of satiation not

592 accounted for in the $\mathrm{S}$ and $\operatorname{tg}$ parameters. In addition, chironomid larvae were

593 sometimes difficult to access if they had settled close to the walls of the containers.

594 This problem became increasingly apparent as fish size increased and contact

595 between the fish's rostrum and the side of the aquaria prevented them from

596 capturing some prey. Such a restriction often resulted in remaining prey at the outer

597 edges of the container. This tank effect was more likely to occur during the $24 \mathrm{~h}$

598 feeding trials than in the short-term 15-min trials. This is another example where

599 tank restrictions might have affected the foraging behavior of the fish and is

600 something to consider when looking to apply any foraging model. Lastly, the model

601 did not consider predator and(or) prey diel effects (Nunn et al. 2011) or prey taxa-

602 dependent gut residence time (Jobling 1987), which have been shown to affect other 603 fish species.

604 The use of laboratory-derived models to address questions in the natural

605 environment has often been criticized because factors that affect prey encounter

606 rates are difficult to replicate in a captive setting (MacKenzie et al. 1990). Caution

607 should always be taken in the application of models developed in a laboratory

608 setting because observed behaviors, as seen in this study, likely differ from those

609 fish experience in their natural environment. It is also important to account for the

610 ecology and biology of the fish under study, as those are likely to differ between taxa 
611 and will influence the study design. These challenges notwithstanding, the model

612 framework presented here can provide a reasonable approach for comparing

613 relative differences in food consumption among age- 0 pallid sturgeon in the natural

614 environment as a function of sturgeon size, prey type, prey density, and water

615 temperatures. Specifically, early life forms of pallid sturgeon are believed to inhabit

616 a wide range of habitats that vary in water temperature and velocity (Wildhaber et

617 al. 2011), prey type and density (Troelstrup and Hergenrader 1989; Hay et al. 2007)

618 and substrates (Gerrity et al. 2008). In this study, we have shown that age-0 pallid

619 sturgeon can sustain growth at low Ephemeroptera and Chironomidae larvae

620 densities ( $\sim 10$ ind. $\left./ \mathrm{m}^{2}\right)$ and cannot rely solely on zooplankton to develop. The

621 behavioral and physiological constraints accounted for by the model help provide

622 conservative estimates of food consumption, and facilitates the hypothesis testing

623 (e.g., diet switch under sub-optimal conditions to confer greater energy gain) given

624 reliable, in situ prey energy density estimates. Applications of the model could use

625 the consumption estimates in combination with a bioenergetics model to simulate

626 growth associated with different river regulation scenarios involving water

627 temperature fluctuations. Similarly, the model could be applied to evaluate

628 conditions found in shallow water habitats (water depth $<1.5 \mathrm{~m}$ and water velocity

$629<0.6 \mathrm{~m} / \mathrm{s}$ ) currently being constructed to enhance recovery of the species

630 (Gemeinhardt et al. 2016).

631

632

633 


\section{Acknowledgements}

635 This manuscript is dedicated to the memory of our friend and colleague, Dr. Robert 636 Klumb. We thank Lauren Kreigel, Wesley Bowman, Thomas Larson, Beth Schmitz 637 and Larissa Bruce for technical assistance in the field and laboratory. We also thank 638 Laura Heironimus, Brian D.S. Graeb, Tobias Rapp and Robert Klumb for helpful 639 discussion and comments. The South Dakota Cooperative Fish and Wildlife Research 640 Unit is jointly sponsored by the U.S. Geological Survey, South Dakota Department of

641 Game, Fish and Parks, South Dakota State University, the Wildlife Management

642 Institute, and the U.S. Fish and Wildlife Service. Funding for this project was

643 provided by the U.S. Army Corps of Engineers (W59XQG11641574). All animals

644 used in this study were reared according to animal use and care guidelines

645 established by South Dakota State University (Animal Welfare Assurance no. A3958-

646 01). Any use of trade names is for descriptive purposes only and does not imply

647 endorsement by the U.S. Government.

648

649 References

650

651 Abràmoff, M.D., Magalhães, P.J., and Ram, S.J. 2004. Image processing with ImageJ.

$652 \quad$ Bioph. 11: 36-42.

653 Alanis, J.G., Sarma, S.S.S., and Nandini, S. 2009. Prey selectivity and functional

654 response by larval red-eyed tetra Moenkhausia Sanctaefilomenae

655 (Steidachner, 1907) (Characiformes: Characidae). Braz. Arch. Biol. Tech.

$656 \quad 52(5): 1209-1216$. 
657 Alexander, M.E., Dick, J.T.A., Wey, O.L.F., Robinson, T.B., and Richardson, D.M. 2014.

658 Existing and emerging high impact invasive species are characterized by

659 higher functional responses than natives. Biol. Lett. 10: 2013946.

660 Anderson, T.W. 2001. Predator responses, prey refuges, and density-dependent 661 mortality of a marine fish. Ecol. 82: 245-257.

662 Bestgen, K.R., Beyers, D.W., and Rice, J.A. 2006. Factors affecting recruitment of 663 young Colorado pikeminnow: synthesis of predation experiments, field 664 studies, and individual-based modeling. Trans. Am. Fish. Soc. 135: 1722$665 \quad 1742$.

666 Bochdansky, A.B., and Deibel, D. 2001. Consequences of model specification for the 667 determination of gut evacuation rates: redefining the linear model. Can. J. $668 \quad$ Fish. Aquat. Sci. 58: 1032-1042.

669 Bolker, B. 2013. emdbook: Ecological models and data in R. version 1.3.4. R Stat. Sof.

670 Braaten, P.J., Fuller, D.B., Lott, R.D., Haddix, T.M., Holte, L.D., Wilson, R.H., Bartron, 671 M.L., Kalie, J.A., DeHaan, P.W., Ardren, W.R., Holm, R.J., and Jaeger, M.E. 2012.

$672 \quad$ Natural growth and diet of known-age pallid sturgeon (Scaphirhynchus albus)

673 early life stages in the upper Missouri River basin, Montana and North 674 Dakota. J. App. Ichthyol. 28(4): 496-504.

675 Brachvogel, R., Meskendahl, L., Herrmann, J.-P., and Temming, A. 2012. Functional 676 responses of juvenile herring and sprat in relation to different prey types. 677 Mar. Biol. 160(2): 465-478. 
678 Buckel, J.A., and Stoner, A.W. 2000. Functional response and switching behavior of 679 young-of-the-year piscivorous bluefish. J. Exp. Mar. Biol. Ecol. 245: 25-41.

680 Chipps, S.R., Klumb, R.A., and Wright, E.B. 2009. Development and application of 681 682 juvenile pallid sturgeon bioenergetics model. South Dakota Department of Game, Fish and Parks, Pierre, South Dakota.

683 Cowan Jr., J.H., Rose, K.A., and DeVries, D.R. 2000. Is density-dependent growth in 684 young-of-the-year fishes a question of critical weight? Rev. Fish. Biol. Fish. 10: 61-89.

Deslauriers, D., Heironimus, L.B., and Chipps, S.R. 2016. Test of a foragingbioenergetics model to evaluate growth dynamics of endangered pallid (Scaphirhynchus albus). U.S Fish and Wildlife Serve, Denver, Colorado. to the Levenberg-Marquardt nonlinear least-squares algorithm found in

694 Fulford, R.S., Rice, J.A., Miller, T.J., Binkowski, F.P., Dettmers, J.M., and Belonger, B. 2006. Foraging selectivity by larval yellow perch (Perca flavescens): MINPACK, plus support for bounds. R Stat. Soft. implications for understanding recruitment in small and large lakes. Can. J. Fish. Aquat. Sci. 63(1): 28-42.

Galarowicz, T.L., and Wahl, D.H. 2005. Foraging by a young-of-the-year piscivore: the 
role of predator size, prey type, and density. Can. J. Fish. Aquat. Sci. 62(10):

700 $2330-2342$.

701 Gemeinhardt, T.R., Gosch, N.J.C., Morris, D.M., Miller, M.L., Welker, T.L., and Bonneau,

$702 \quad$ J.L. 2016. Is shallow water a suitable surrogate for assessing efforts to

703 address pallid sturgeon population declines? Riv. Res. App. 32: 734-743.

704 Gerrity, P.C., Guy, C.S., and Gardner, W.M. 2008. Habitat use of juvenile pallid

705 sturgeon and shovelnose sturgeon with implications for water-level

706 management in a downstream reservoir. N. Am. J. Fish. Man. 28: 832-843.

707 Giacomini, H.C., Shuter, B.J., and Lester, N.P. 2013. Predator bioenergetics and the 708 prey size spectrum: Do foraging costs determine fish production? J. Theor.

$709 \quad$ Biol. 332: 249-260.

710 Gill, A.B., and Hart, P.J.B. 1994. Feeding behaviour and prey choice of the threespine stickleback: the interacting effects of prey size, fish size and stomach fullness. An. Behav. 47(4): 921-932.

713 Grohs, K.L. 2008. Macroinvertebrate composition and patterns of prey use by

$714 \quad$ juvenile pallid sturgeon (Scaphirhynchus albus) in the Missouri River, South

715 Dakota and Nebraska. M.S. Thesis, South Dakota State University, Brookings,

$716 \quad$ South Dakota

717 Grohs, K.L., Klumb, R.A., Chipps, S.R., and Wanner, G.A. 2009. Ontogenetic patterns in 718 prey use by pallid sturgeon in the Missouri River, South Dakota and

719 Nebraska. J. App. Ichthyol. 25(s2): 48-53.

720 Gustafsson, P., Bergman, E., and Greenberg, L.A. 2010. Functional response and size- 
721

722

723

724

725

726

727

728

729

730

731

732

733

734

735

736

737

738

739

740

741 dependent foraging on aquatic and terrestrial prey by brown trout (Salmo trutta L.). Ecol. Fresh. Fish 19(2): 170-177.

Harrison, A.B., William, T.S., and Killgore, K.J. 2014. Feeding habitats of young-ofyear sturgeon Scaphirhynchus spp. in the lower Mississippi River. Am. Midl. Nat. 171: 54-67.

Hay, C.H., Franti, T.G., Marx, D.B., Peters, E.J., and Hesse, L.W. 2007. Macroinvertebrate drift density in relation to abiotic factors in the Missouri River. Hydrobiologia 598(1): 175-189.

Heironimus, L.B. 2015. The development and application of a larval pallid sturgeon (Scaphirhynchus albus) bioenergetics model. South Dakota State University, Brookings, South Dakota.

Hilborn, R., and Mangel, M. 1997. The ecological detective: confronting models with data. Princeton University Press, Princeton, New Jersey, 330 pp.

Holling, C.S. 1959. The components of predation as revealed by a study of smallmammal predation of the European pine sawfly. Can. Ent. 91(5): 293-320.

Houde, E.D., and Schekter, R.C. 1980. Feeding by marine fish larvae: developmental and functional responses. Environ. Biol. Fish. 5(4): 315-334.

Hrabik, R.A., Herzog, D.P., Ostendorf, D.E., and Petersen, M.D. 2007. Larvae provide first evidence of successful reproduction by pallid sturgeon, Scaphirhynchus albus, in the Mississippi River. J. App. Ichthyol. 23(4): 436-443. 
742

743

744

745

746

747

748 Hunter, J.R. 1972. Swimming and feeding behavior of larval anchovy Engraulis

749

750 James, D.A., Csargo, I.J., Von Eschen, A., Thul, M.D., Baker, J.M., Hayer, C.-A., Howell, J.,

751 Krause, J., Letvin, A., and Chipps, S.R. 2012. A generalized model for

752

753

754

755

756

757

758

759

760

761

762

Essington, T.E., Gaichas, S., Anderson, T.W., Brodeur, R.D., Chan, K.-S.S., Chen, K., Englund, G., Frank, K.T., Freitas, V., Hixon, M.A., Hurst, T., Johnson, D.W., Kitchell, J.F., Reese, D., Rose, G.A., Sjodin, H., Sydeman, W.J., van der Veer, H.W., Vollset, K., and Zador, S. 2011. Functional responses and scaling in predator-prey interactions of marine fishes: contemporary issues and emerging concepts. Ecol. Lett. 14: 1288-1299. mordax. Fish. Bull. 70(3): 821-838. estimating the energy density of invertebrates. Fresh. Sci. 31(1): 69-77

Jeschke, J.M., and Hohberg, K. 2008. Predicting and testing functional responses: An example from a tardigrade-nematode system. Bas. App. Ecol. 9(2): 145-151.

Jeschke, J.M., Kopp, M., and Tollrian, R. 2002. Predator functional responses: discriminating between handling and digesting prey. Ecol. Mono. 72: 95-112.

Jobling, M. 1987. Influences of food particle size and dietary energy content on patterns of gastric evacuation in fish: test of a physiological model of gastric emptying. J. Fish Biol. 30(3): 299-314.

Jönsson, M., Ranåker, L., Anders Nilsson, P., Brönmark, C. 2013. Foraging efficiency and prey selectivity in a visual predator: differential effects of turbid and humic water. Can. J. Fish. Aquat. Sci. 70: 1685-1690. 
763 Kappenman, K.M., Toner, M., Illgen, J., and Barrows, F.T. 2011. The effect of diet on 764 growth and survival of first feeding pallid sturgeon Scaphirhynchus albus. J.

765 App. Ichthyol. 27(2): 755-760.

766

Karjalainen, J.S., Ollikainen, S., and Viljanen, M. 1996. Estimation of the year-class of 767 newly hatched fish larvae in Finnish lakes - how sampling design can

768 influence abundance estimations? Arch. Hydrobiol. 50: 73-80.

769 Kynard, B., Parker, E., Parker, T. 2005. Behavior of early life intervals of Klamath

770 River green sturgeon, Acipenser medirostris, with a note on body color.

$771 \quad$ Environ. Biol Fish. 72: 85-97.

772 Lefébure, R., Larsson, S., and Byström, P. 2014. Temperature and size-dependent

773 attack rates of the three-spined stickleback (Gasterosteus aculeatus); are

774 sticklebacks in the Baltic Sea resource-limited? J. Exp. Mar. Biol. Ecol. 451:

$775 \quad 82-90$

776 MacKenzie, B.R., Leggett, W.C., and Peters, R.H. 1990. Estimating larval fish ingestion

777 rates: can laboratory derived values be reliably extrapolated to the wild?

778 Mar. Ecol. Prog. Ser. 67: 209-225.

779 Madenjian, C.P., and Carpenter, S.R. 1991. Individual-based model for growth of 780 young-of-the-year walleye: a piece of the recruitment puzzle. Ecol. App. 1(3): $781 \quad 268-279$.

782 Marcotte, B.M., and Browman, H.I. 1985. Foraging behaviour in fishes: perspectives 783 on variance. Environ. Biol Fish. 7: 25-34. 
784 Mazur, M.M., and Beauchamp, D.A. 2003. A comparison of visual prey detection 785 among species of piscivorous salmonids: effects of light and low turbidity.

786 Environ. Biol Fish. 67: 397-405.

787 Miller, T.J., Crowder, L.B., and Rice, J.A. 1992. Body size and the ontogeny of the 788 functional response in fishes. Can. J. Fish. Aquat. Sci. 49: 805-812.

789 Morita, K., and Yokota, A. 2002. Population viability of stream-resident salmonids 790 after habitat fragmentation: a case study with white-spotted charr (Salvelinus 791 leucomaenis) by an individual based model. Ecol. Mod. 155(1): 85-94.

792 Moustahfid, H., Tyrrell, M.C., Link, J.S., Nye, J.A., Smith, B.E., and Gamble, R.J. 2010.

793 Functional feeding responses of piscivorous fishes from the northeast US $794 \quad$ continental shelf. Oecol. 163(4): 1059-1067.

795 Munk, P. 1995. Foraging behaviour of larval cod (Gadus morhua) influenced by prey 796 density and hunger. Mar. Biol. 122(2): 205-212.

797 Nes, E.H.v., Lammens, E.H.R.R., and Scheffer, M. 2002. PISCATOR, an individual798 based model to analyze the dynamics of lake fish communities. Ecol. Mod. $799 \quad$ 152(2-3): 261-278.

800 Nunn, A.D., Tewson, L.H., and Cowx, I.G. 2011. The foraging ecology of larval and 801 juvenile fishes. Rev. Fish Biol. Fish. 22(2): 377-408.

802 Paradis, Y, Mingelbier, M, and Brodeur, P. 2008. Comparisons of catch and 803 precision of pop nets, push nets, and seines for sampling larval and juvenile 804 yellow perch. N. Am. J. Fish. Man. 28: 1554-1562. 
805 Peña-Aguado, F., Nandini, S., and Sarma, S.S.S. 2009. Functional response of Ameca 806 splendens (Family Goodeidae) fed cladocerans during the early larval stage. 807 Aqua. Res. 40(14): 1594-1604.

808 Persson, L. 1987. Effects of habitat and season on competitive interactions between 809 roach (Rutilus rutilus) and perch (Perca fluviatilis). Oecologia 73(2): 170-177.

810 Pyke, G.H. 2003. Optimal foraging theory: A critical review. Annu. Rev. Ecol. Syst. 15: $811 \quad 523-575$.

812 R Core Team. 2014. R: A language and environment for statistical computing. R 813 Foundation for Statistical Computing, Vienna, Austria.

814 Rall, B.C., Brose, U., Hartvig, M., Kalinkat, G., Schwarzmuller, F., Vucic-Pestic, O., and 815 Petchey, O.L. 2012. Universal temperature and body-mass scaling of feeding 816 rates. Philos. Trans. R. Soc. B: Biol. Sci. 367(1605): 2923-2934.

817 Rapp, T. 2015. Determinants of growth and survival of larval pallid sturgeon: a 818 combined laboratory and field approach. South Dakota State University, 819 Brookings, South Dakota.

820 Rice, J.A., and Cochran, P.A. 1983. Independent evaluation of a bioenergetics model 821 for largemouth bass. Ecol. 65(3): 732-739.

822 Rose, K.A., Rutherford, E.S., McDermot, D.S., Forney, J.L., and Mills, E.L. 1999.

823 Individual-based model of yellow perch and walleye populations in Oneida $824 \quad$ lake. Ecol. Mono. 69(2): 127-154.

825 Rose, K.A., Kimmerer, W.J., Edwards, K.P., and Bennett, W.A. 2013. Individual-based 
modeling of delta smelt population dynamics in the upper San Francisco estuary: II. Alternative baselines and good versus bad years. Trans. Am. Fish. Soc. 142: 1260-1272

829 Sechler, R.S., Phelps, Q.E., Tripp, S.J., Garvey, J.E., Herzog, D.P., Ostendorf, D.E., 830 Ridings, J.W., Crites, J.W., and Hrabik, R.A. 2012. Habitat for age-0 Shovelnose 831 and Pallid Sturgeon in a large river: Interactions among abiotic factors, food, 832 and energy intake. N. Am. J. Fish. Man. 32: 24-31.

833 Sherwood, G.D., Pazzia, I., Moeser, A., Hontela, A., and Rasmussen, J.B. 2002. Shifting 834 gears: enzymatic evidence for the energetic advantage of switching diet in 835 wild-living fish. Can. J. Fish. Sci. 59: 229-241.

836 Snyder, D.E. 2002. Pallid and shovelnose sturgeon larvae - morphological 837 description and identification. J. App. Ichthyol. 18(4-6): 240-265.

838 Soetaert, K., Petzoldt, T., and Setzer, R.W. 2010. Solving differential equations in R: 839 package deSolve. J. Stat. Soft. 33: 1-25.

840 Spaargaren, D.H. 1979. Hydrodynamic properties of benthic marine crustacea. I. 841 Specific gravity and drag coefficients. Mar. Ecol. Prog. Ser. 1: 351-359.

842 Taverny, C., Lepage, M., Piefort, S., Dumont, P., Rochard, E. 2002. Habitat selection by 843 juvenile European sturgeon Acipenser sturio in the Gironde estuary (France). $844 \quad$ J. Appl. Ichthyol. 18: 536-541.

845 Troelstrup Jr., N.H., and Hergenrader, G.L. 1989. Effect of hydropower peaking flow 846 fluctuations on community structure and feeding guilds of invertebrates 

colonizing artificial substrates in a large impounded river. Hydrobiologia. 199(3): 217-228.

849 850 851 852 853

Wanzenböck, J. 1995. Changing handling times during feeding and consequences for prey size selection of 0+ zooplanktivorous fish. Oecologia 104(3): 372-378.

Ware, K.M., Henne, J.P., Hickson, B.H., Charlesworth, K. 2006. Evaluation of six feeding regimens for survival and growth of shortnose sturgeon fry. N. Am. J. Aqua. 68: 211-216.

Watz, J., Bergman, E., Piccolo, J., and Greenberg, L. 2014. Prey capture rates of two species of salmonids (Salmo trutta and Thymallus thymallus) in an artificial stream: effects of temperature on their functional response. Mar. Fresh. Behav. Physiol. 47(2): 93-99.

Webb, M.A.H., Williams, J.E., and Hildebrand, L.R. 2005. Recovery program review for endangered pallid sturgeon in the Upper Missouri River Basin. Rev. Fish. Sci. 13: 165-176.

Wildhaber, M.L., DeLonay, A.J., Papoulias, D.M., Galat, D.L., Jacobson, R.B., Simpkins, D.G., Braaten, P.J., Korschgen, C.E., and Mac, M.J. 2011. Identifying structural elements needed for development of a predictive life-history model for pallid and shovelnose sturgeons. J. App. Ichthyol. 27(2): 462-469. composition of juvenile and adult pallid sturgeon, Scaphirhynchus albus (Forbes \& Richardson, 1905), in the channelized lower Missouri River. J. 
868 Appl. Ichthyol. 30(6): 1133-1140.

869 Winkle, W.V., Rose, K.A., Shuter, B.J., Jager, H.I., and Holcomb, B.D. 1997. Effects of

870 climatic temperature change on growth, survival, and reproduction of

871 rainbow trout: predictions from a simulation model. Can. J. Fish. Aquat. Sci.

$872 \quad$ 54(11): 2526-2542.

873 
Table 1. Conditions used to generate the functional feeding responses of age-0 pallid sturgeon. All trials lasted 15 min.

\begin{tabular}{ccccc}
\hline $\begin{array}{c}\text { Total Length } \\
\mathrm{mm}\end{array}$ & $\begin{array}{c}\text { Temp. } \\
{ }^{\circ} \mathrm{C}\end{array}$ & $\begin{array}{c}\text { Daphnia Density } \\
\text { inds/L }\end{array}$ & $\begin{array}{c}\text { Chironomidae/Mayfly Density } \\
\text { inds/m }{ }^{2}\end{array}$ & $\begin{array}{c}\text { Chironomidae size }{ }^{1,2} \\
\text { class }\end{array}$ \\
\hline 19 & $14,18,24$ & $15,30,45,60,75,90$ & $150,300,450,600,750,900$ & Small,Medium,Mixed,Large \\
20 & $14,18,24$ & $15,30,45,60,75,90$ & $150,300,450,600,750,900$ & Small,Medium,Mixed,Large \\
30 & $14,18,24$ & $15,30,45,60,75,90$ & $150,300,450,600,750,900$ & Small,Medium,Mixed,Large \\
40 & $14,18,24$ & $18,36,54,72,90$ & $180,360,540,720,900$ & Small,Medium,Mixed,Large \\
50 & $14,18,24$ & $18,36,54,72,90$ & $180,360,540,720,900$ & Small,Medium,Mixed,Large \\
70 & $14,18,24$ & NA & $180,360,540,720,900^{2}$ & Mixed
\end{tabular}

1: Only mixed size classes for chironomids were tested with and without a sand substrate

2: Only chironomids were tested for $70 \mathrm{~mm}$ sturgeon 
Table 2. Conditions used to evaluate the age-0 pallid sturgeon foraging model along with their respective evaluation metrics. All trials ( $\mathrm{n}=5$ per combination) lasted $24 \mathrm{~h}$ and were performed using a sand substrate. Mixed sizes of chironomids (9.38 mm \pm 2.71 S.D.) were used for all trials. A total of 210 fish was used to evaluate the model. Values in parentheses represent 1 S.D., C.I. indicates the $97.5 \%$ confidence intervals while MSE symbolizes the mean square error components.

\begin{tabular}{|c|c|c|c|c|c|c|c|c|}
\hline \multicolumn{4}{|c|}{ Experimental Conditions } & \multicolumn{5}{|c|}{ Model Evaluation } \\
\hline Size & Temperature & Prey given & Container Area & Intercept C.I. & Slope C.I. & MSE mean & MSE slope & MSE residual \\
\hline $\mathrm{mm}$ & ${ }^{\circ} \mathrm{C}$ & individuals & $\mathrm{m}^{2}$ & $1.25-98.75 \%$ & $1.25-98.75 \%$ & $\%$ & $\%$ & $\%$ \\
\hline $18.90(0.10)$ & $14,18,24$ & $2,4,6$ & 0.0095 & $-1.68-0.26$ & $1.00-1.66$ & 4 & 14 & 81 \\
\hline $20.81(0.42)$ & $14,18,24$ & $3,6,9$ & 0.0095 & $-0.83-2.61$ & $-0.08-1.01$ & 18 & 10 & 72 \\
\hline $44.42(1.09)$ & $14,18,24$ & $3,6,9$ & 0.0095 & $-0.74-1.67$ & $0.61-1.01$ & 20 & 8 & 72 \\
\hline $108.27(1.08)$ & $14,18,24$ & $25,50,75,100,125$ & 0.125 & $-8.10-9.16$ & $0.90-1.17$ & 5 & 1 & 95 \\
\hline
\end{tabular}


Table 3. Functional feeding response coefficients for age-0 pallid sturgeon of different sizes feeding on zooplankton, Chironomidae (mixed treatment) or Ephemeroptera larvae. All trials were performed on a bare and sand substrate for chironomids. Values in parentheses represent the standard error. Temp represents water temperature, $\mathrm{L}$ is fish total length, a is the attack coefficient, $\mathrm{T}_{\mathrm{h}}$ is the handling time, and $\mathrm{N}_{\mathrm{m}}$ is the mean number of prey consumed by a fish over a 15 min period. $\mathrm{N}_{\mathrm{m}}$ was only calculated in the absence of a significant functional feeding response. Data used to generate the coefficients can be seen in Figure 1.

\begin{tabular}{|c|c|c|c|c|c|c|c|c|c|c|c|c|c|}
\hline \multirow[b]{2}{*}{$\mathrm{L}$} & \multirow[b]{2}{*}{ Temp } & \multicolumn{3}{|c|}{ Zooplankton } & \multicolumn{3}{|c|}{ Ephemeroptera } & \multicolumn{3}{|c|}{ Chironomidae w/o sand } & \multicolumn{3}{|c|}{ Chironomidae $\mathrm{w} /$ sand } \\
\hline & & $a$ & $T_{h}$ & $\mathrm{~N}_{\mathrm{m}}$ & $a$ & $T_{h}$ & $\mathrm{~N}_{\mathrm{m}}$ & $a$ & $\mathrm{~T}_{\mathrm{h}}$ & $\mathrm{N}_{\mathrm{m}}$ & $a$ & $\mathrm{~T}_{\mathrm{h}}$ & $\mathrm{N}_{\mathrm{m}}$ \\
\hline $\mathrm{mm}$ & ${ }^{\circ} \mathrm{C}$ & $\mathrm{L} / \mathrm{min}$ & $\min$ & eaten/15 $\mathrm{min}$ & $\mathrm{m}^{2} / \mathrm{min}$ & $\min$ & eaten/15 $\mathrm{min}$ & $\mathrm{m}^{2} / \mathrm{min}$ & $\min$ & eaten/15 $\mathrm{min}$ & $\mathrm{m}^{2} / \mathrm{min}$ & $\min$ & eaten $/ 15 \mathrm{~min}$ \\
\hline \multirow[t]{3}{*}{19} & 14 & NA & NA & $0.03(0.03)$ & NA & NA & $0.10(0.07)$ & NA & NA & $0.03(0.03)$ & NA & NA & $0.003(0.001)$ \\
\hline & 18 & NA & NA & $0.10(0.06)$ & NA & NA & $0.27(0.10)$ & NA & NA & $0.03(0.03)$ & NA & NA & $0.003(0.001)$ \\
\hline & 24 & NA & NA & $0.17(0.07)$ & NA & NA & $0.27(0.08)$ & NA & NA & $0.37(0.11)$ & NA & NA & $0.006(0.002)$ \\
\hline \multirow[t]{3}{*}{20} & 14 & NA & NA & $0.10(0.07)$ & NA & NA & $0.10(0.06)$ & NA & NA & $0.23(0.09)$ & NA & NA & $0.07(0.05)$ \\
\hline & 18 & NA & NA & $0.07(0.05)$ & NA & NA & $0.93(0.22)$ & NA & NA & $0.57(0.11)$ & NA & NA & $0.13(0.06)$ \\
\hline & 24 & NA & NA & $0.53(0.14)$ & NA & NA & $0.10(0.07)$ & NA & NA & $0.20(0.07)$ & NA & NA & $0.17(0.11)$ \\
\hline \multirow[t]{3}{*}{30} & 14 & NA & NA & $0.30(0.10)$ & $0.07(0.05)$ & $2.41(1.50)$ & NA & $0.03(0.04)$ & $11.84(6.69)$ & NA & NA & NA & $0.03(0.03)$ \\
\hline & 18 & $0.06(0.09)$ & $9.16(4.57)$ & NA & NA & NA & $0.40(0.15)$ & $0.05(0.03)$ & $3.51(1.83)$ & NA & NA & NA & $0.47(0.14)$ \\
\hline & 24 & $0.10(0.16)$ & $7.25(3.41)$ & NA & NA & NA & $0.17(0.10)$ & NA & NA & $0.27(0.17)$ & NA & NA & $0.17(0.10)$ \\
\hline \multirow[t]{3}{*}{40} & 14 & $0.01(0.00)$ & $1.47(0.64)$ & NA & $0.04(0.05)$ & $5.91(2.56)$ & NA & $0.11(0.10)$ & $2.66(0.83)$ & NA & $0.02(0.02)$ & $6.11(2.86)$ & NA \\
\hline & 18 & $0.05(0.03)$ & $1.72(0.37)$ & NA & $0.02(0.02)$ & $2.06(3.25)$ & NA & $0.05(0.04)$ & $1.59(1.21)$ & NA & $0.14(0.29)$ & $8.59(2.39)$ & NA \\
\hline & 24 & $0.03(0.03)$ & $1.22(0.60)$ & NA & $0.32(0.53)$ & $5.15(0.84)$ & NA & $0.18(0.13)$ & $2.24(0.42)$ & NA & $0.14(0.22)$ & $6.46(1.52)$ & NA \\
\hline \multirow[t]{3}{*}{50} & 14 & $0.02(0.01)$ & $2.36(0.60)$ & NA & $0.01(0.01)$ & $0.50(3.05)$ & NA & $0.10(0.05)$ & $1.78(0.38)$ & NA & $0.18(0.16)$ & $3.15(0.58)$ & NA \\
\hline & 18 & $0.05(0.02)$ & $0.83(0.21)$ & $\mathrm{Na}$ & $0.07(0.05)$ & $1.36(0.73)$ & NA & $0.32(0.20)$ & $1.26(0.21)$ & NA & $0.11(0.06)$ & $1.20(0.46)$ & NA \\
\hline & 24 & $0.04(0.02)$ & $0.53(0.25)$ & NA & $0.04(0.03)$ & $2.61(1.75)$ & NA & $0.02(0.02)$ & $0.60(2.14)$ & NA & $0.18(0.25)$ & $3.59(0.90)$ & NA \\
\hline
\end{tabular}




\section{Table 3 continued}

$\begin{array}{lll}70 & 14 & N A\end{array}$

18 NA

NA NA

NA

NA

$\begin{array}{lll}\text { NA } & 0.14(0.13) & 0.44(0.64) \\ \text { NA } & 0.39(0.20) & 1.13(0.17)\end{array}$

NA

$\begin{array}{ll}\text { NA } & \text { NA } \\ \text { NA } & \text { NA }\end{array}$

NA

$0.41(0.45) \quad 0.99(0.30)$

$\begin{array}{llll}\text { NA } & 0.29(0.41) & 2.19(0.58) & \text { NA } \\ \text { NA } & 0.30(0.28) & 1.44(0.32) & \text { NA } \\ \text { NA } & 0.20(0.11) & 1.20(0.28) & \text { NA }\end{array}$


Table 4. Functional feeding response coefficients for fish of different sizes of pallid sturgeon feeding on small, medium and large size classes of Chironomidae larvae. All trials were performed on a bare substrate. Values in () representing the standard error. $a$ is the attack coefficient, $\mathrm{T}_{\mathrm{h}}$ is the handling time, and $\mathrm{N}_{\mathrm{m}}$ is the mean number of prey consumed by a fish over a 15 min period. $\mathrm{N}_{\mathrm{m}}$ was only calculated in the absence of a significant functional feeding response. Data used to generate the coefficients can be seen in Figure 2.

\begin{tabular}{|c|c|c|c|c|c|c|c|c|c|c|}
\hline \multirow[b]{2}{*}{$\begin{array}{l}\text { Total Length } \\
\mathrm{mm}\end{array}$} & \multirow[b]{2}{*}{$\begin{array}{c}\text { Temperature } \\
{ }^{\circ} \mathrm{C} \\
\end{array}$} & \multicolumn{3}{|c|}{ Small chironomids } & \multicolumn{3}{|c|}{ Medium chironomids } & \multicolumn{3}{|c|}{ Large chironomids } \\
\hline & & $\begin{array}{c}a \\
\mathrm{~m}^{2} / \min \end{array}$ & $\begin{array}{l}T_{h} \\
\min \end{array}$ & $\begin{array}{c}N_{m} \\
\text { eaten/15 min }\end{array}$ & $\begin{array}{c}a \\
\mathrm{~m}^{2} / \min \end{array}$ & $\begin{array}{c}\mathrm{T}_{\mathrm{h}} \\
\mathrm{min}\end{array}$ & $\begin{array}{c}N_{m} \\
\text { eaten/15 min }\end{array}$ & $\begin{array}{c}a \\
\mathrm{~m}^{2} / \min \end{array}$ & $\begin{array}{l}\mathrm{T}_{\mathrm{h}} \\
\min \end{array}$ & $\begin{array}{c}\mathrm{N}_{\mathrm{m}} \\
\text { eaten/15 min }\end{array}$ \\
\hline \multirow[t]{3}{*}{19} & 14 & NA & NA & $0.017(0.002)$ & NA & NA & NA & NA & NA & NA \\
\hline & 18 & NA & NA & $0.017(0.003)$ & NA & NA & NA & NA & NA & NA \\
\hline & 24 & NA & NA & $0.041(0.006)$ & NA & NA & NA & NA & NA & NA \\
\hline \multirow[t]{3}{*}{20} & 14 & NA & NA & $0.53(0.12)$ & NA & NA & $0.03(0.03)$ & NA & NA & NA \\
\hline & 18 & NA & NA & $0.83(0.14)$ & NA & NA & $0.13(0.06)$ & NA & NA & NA \\
\hline & 24 & NA & NA & $0.30(0.11)$ & NA & NA & $0.03(0.03)$ & NA & NA & NA \\
\hline \multirow[t]{3}{*}{30} & 14 & $0.14(0.22)$ & $4.32(2.06)$ & NA & $0.02(0.02)$ & 7.37 (9.39) & 0 & NA & NA & $0.27(0.15)$ \\
\hline & 18 & $0.28(0.20)$ & $1.40(0.54)$ & NA & $0.19(0.16)$ & $1.74(0.88)$ & 0 & NA & NA & $0.57(0.12)$ \\
\hline & 24 & $0.52(0.73)$ & $1.57(0.59)$ & NA & $0.07(0.06)$ & $1.50(1.68)$ & 0 & $0.05(0.06)$ & $8.03(3.63)$ & NA \\
\hline \multirow[t]{3}{*}{40} & 14 & $0.05(0.03)$ & $0.92(0.90)$ & NA & $0.14(0.17)$ & $2.19(0.82)$ & 0 & $0.03(0.03)$ & $3.38(1.93)$ & NA \\
\hline & 18 & $0.09(0.04)$ & $0.77(0.37)$ & NA & $0.04(0.05)$ & $0.98(1.75)$ & 0 & $0.03(0.03)$ & $9.87(2.29)$ & NA \\
\hline & 24 & $0.89(1.62)$ & $1.26(0.24)$ & NA & $0.73(1.16)$ & $1.91(0.29)$ & 0 & $0.19(0.25)$ & $4.53(0.87)$ & NA \\
\hline \multirow[t]{3}{*}{50} & 14 & $0.10(0.06)$ & $0.63(0.48)$ & NA & $0.09(0.03)$ & $1.00(0.32)$ & 0 & $0.07(0.03)$ & $2.47(0.65)$ & NA \\
\hline & 18 & $0.08(0.04)$ & $0.33(0.46)$ & NA & $0.14(0.07)$ & $0.36(0.35)$ & 0 & $0.49(0.60)$ & $1.58(0.30)$ & NA \\
\hline & 24 & $0.09(0.04)$ & $0.31(0.50)$ & NA & $0.10(0.07)$ & $1.34(0.68)$ & 0 & $0.31(0.58)$ & $4.91(0.91)$ & NA \\
\hline
\end{tabular}


Table 5. Multiple regression coefficient estimates and standard errors (SE) for $\log _{\mathrm{e}}\left(\mathrm{N}^{\prime}\right)$ (equation 2). As the most common prey type for age-0 pallid sturgeon, the Mixed Chironomidae treatment was used as the reference prey type. To estimate consumption $\left(\log _{\mathrm{e}} \mathrm{N}^{\prime}\right)$ for other prey types that were coded as dummy variables, their parameter estimates are added (or substracted) to the intercept value.

\begin{tabular}{lcccc}
\hline Parameter & Estimate & $\mathrm{SE}$ & t-value & P-value \\
\hline Intercept $\mathrm{t}^{\mathrm{a}}$ & -17.75 & 0.31 & -57.27 & $<0.001$ \\
Loge $_{\mathrm{e}}$ Length) & 4.3 & 0.07 & 57.874 & $<0.001$ \\
Temperature $\left({ }^{\circ} \mathrm{C}\right)$ & 0.03 & 0.01 & 4.272 & $<0.001$ \\
Prey density & 1.4 & 0.1 & 13.559 & $<0.001$ \\
Large Chironomidae & 0.779 & 0.131 & 5.936 & $<0.001$ \\
Medium Chironomidae & 1.711 & 0.119 & 14.324 & $<0.001$ \\
Mixed Chironomidae Bare & 1.365 & 0.094 & 14.517 & $<0.001$ \\
Small Chironomidae & 2.134 & 0.113 & 18.969 & $<0.001$ \\
Mayfly & 1.502 & 0.113 & 13.349 & $<0.001$ \\
Zooplankton & 1.399 & 0.112 & 12.437 & $<0.001$ \\
\hline
\end{tabular}

a Intercept value based on Mixed Chironomidae with sand substrate

${ }^{\mathrm{b}}$ Proportion of maximum value 


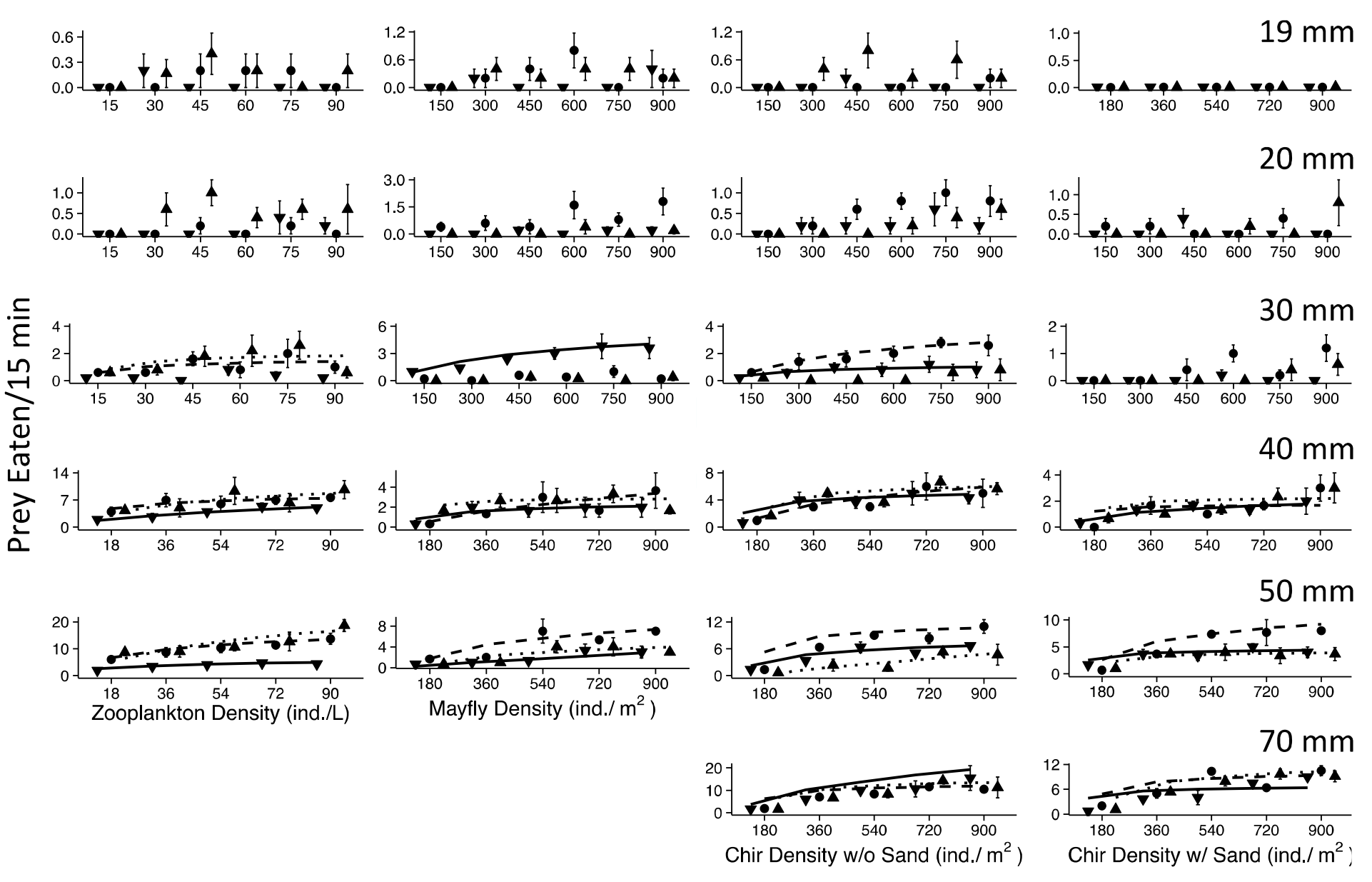

Figure 1. Functional relationships depicting the number of prey consumed based on the initial prey densities for different pallid sturgeon size classes feeding on different prey taxa. Trials at different temperatures are indicated by $(-\nabla-)$ for $14^{\circ} \mathrm{C}$, $(--\bullet--)$ for $18^{\circ} \mathrm{C}$ and $(\cdot \cdot \mathbf{\Delta} \cdot \cdot)$ for $24^{\circ} \mathrm{C}$. Trials with a missing regression line indicate a lack of prey density effect. Regression coefficients can be seen in Table 3. Note: y-axes scales differ depending on treatment. 

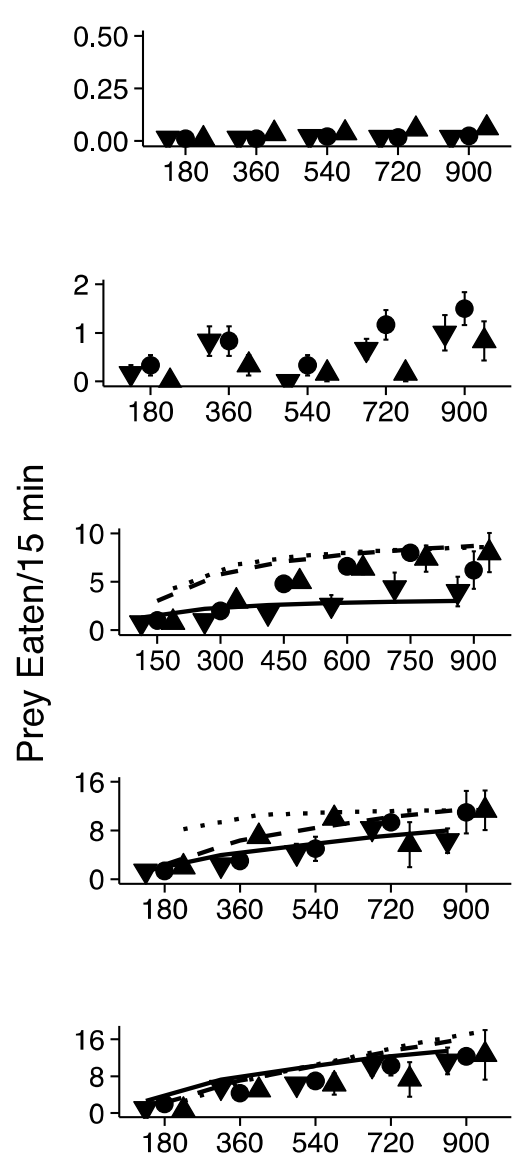

Sml Chir Density (ind./ $\mathrm{m}^{2}$ )
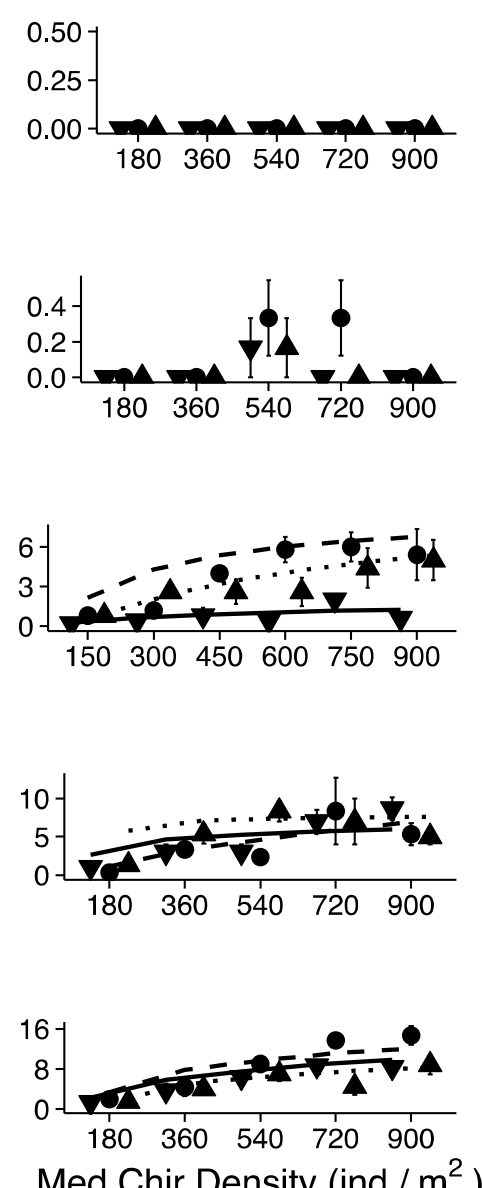
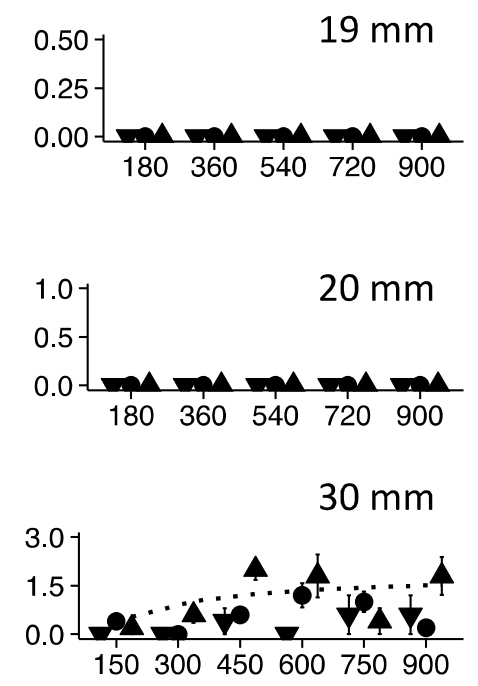

$40 \mathrm{~mm}$
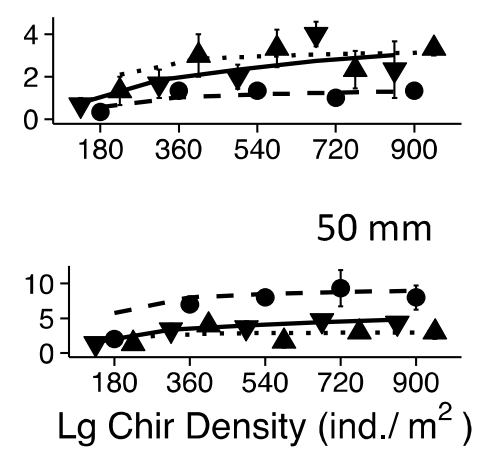

Figure 2. Functional relationships depicting the number of prey consumed based on the initial prey densities for different pallid sturgeon size classes feeding on different Chironomidae larvae size classes. Trials at different temperatures are indicated by $(-\boldsymbol{\nabla}-)$ for $14^{\circ} \mathrm{C},\left(--\boldsymbol{-}^{-}\right)$for $18^{\circ} \mathrm{C}$ and $(\cdot \mathbf{\Delta} \cdot \cdot)$ for $24^{\circ} \mathrm{C}$. Trials with a missing regression line indicate a lack of prey density effect. Regression coefficients can be seen in Table 4. Note: y-axes scales differ depending on treatment. 


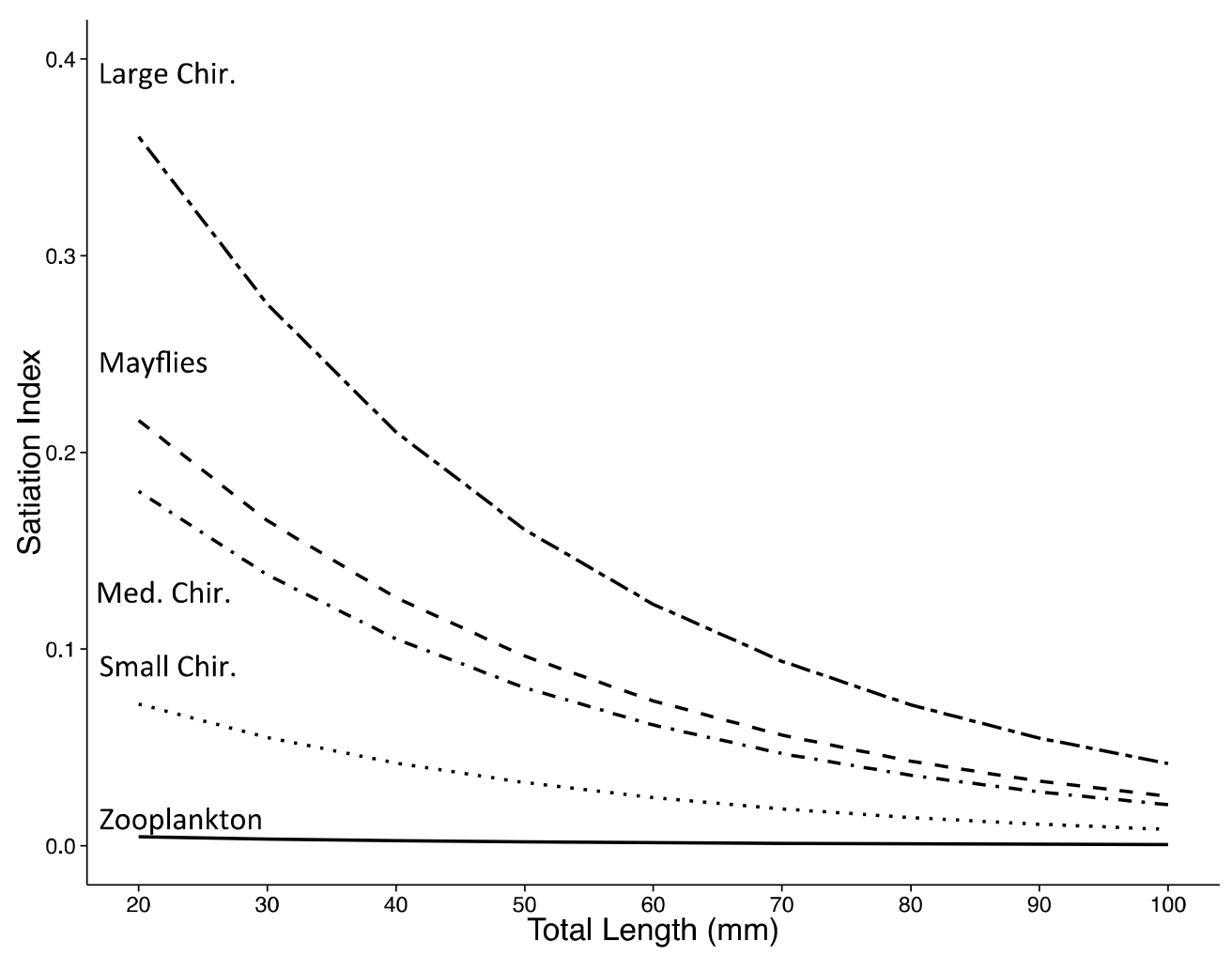

Figure 3. Variation of the satiation index (S; equation 7) with fish total length (in $\mathrm{mm}$ ) and prey type. An $\mathrm{S}$ value of 0.1 indicates that 10 prey items can fit in the gut at a given time. 

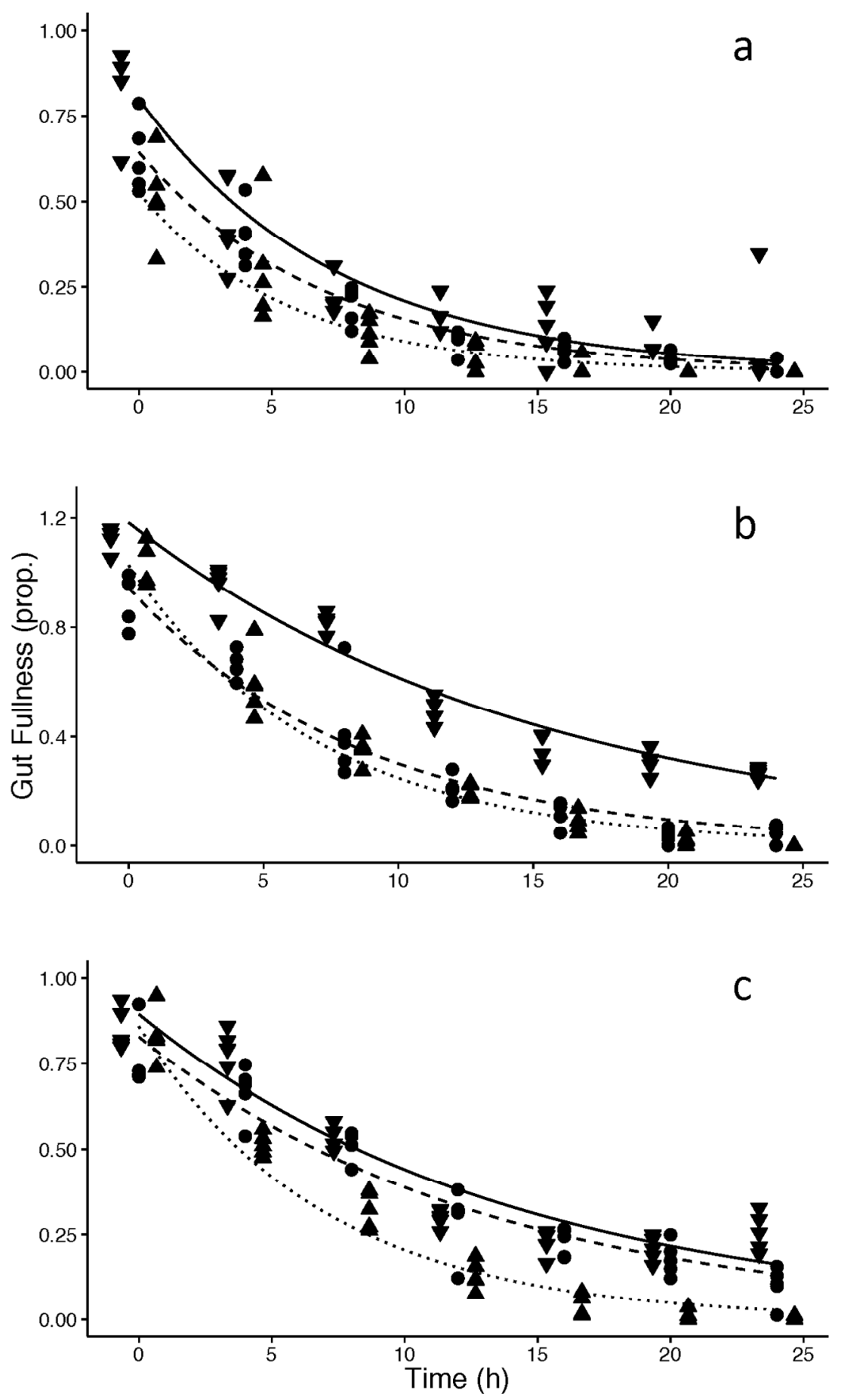

Figure 4. Changes in gut fullness for three sizes of pallid sturgeon a) $41.2 \mathrm{~mm} \mathrm{~b}$ ) $69.5 \mathrm{~mm}$, or c) 107.6 at $14^{\circ} \mathrm{C}(-\boldsymbol{\nabla}-), 18^{\circ} \mathrm{C}\left(--\mathbf{-}^{-}\right)$or $24^{\circ} \mathrm{C}(\cdot \boldsymbol{\Delta} \cdot \cdot)$. Symbols from the same time interval were separated to avoid overlap. Curves depict the proportion of gut fullness (0-1) as it decreases over time. 


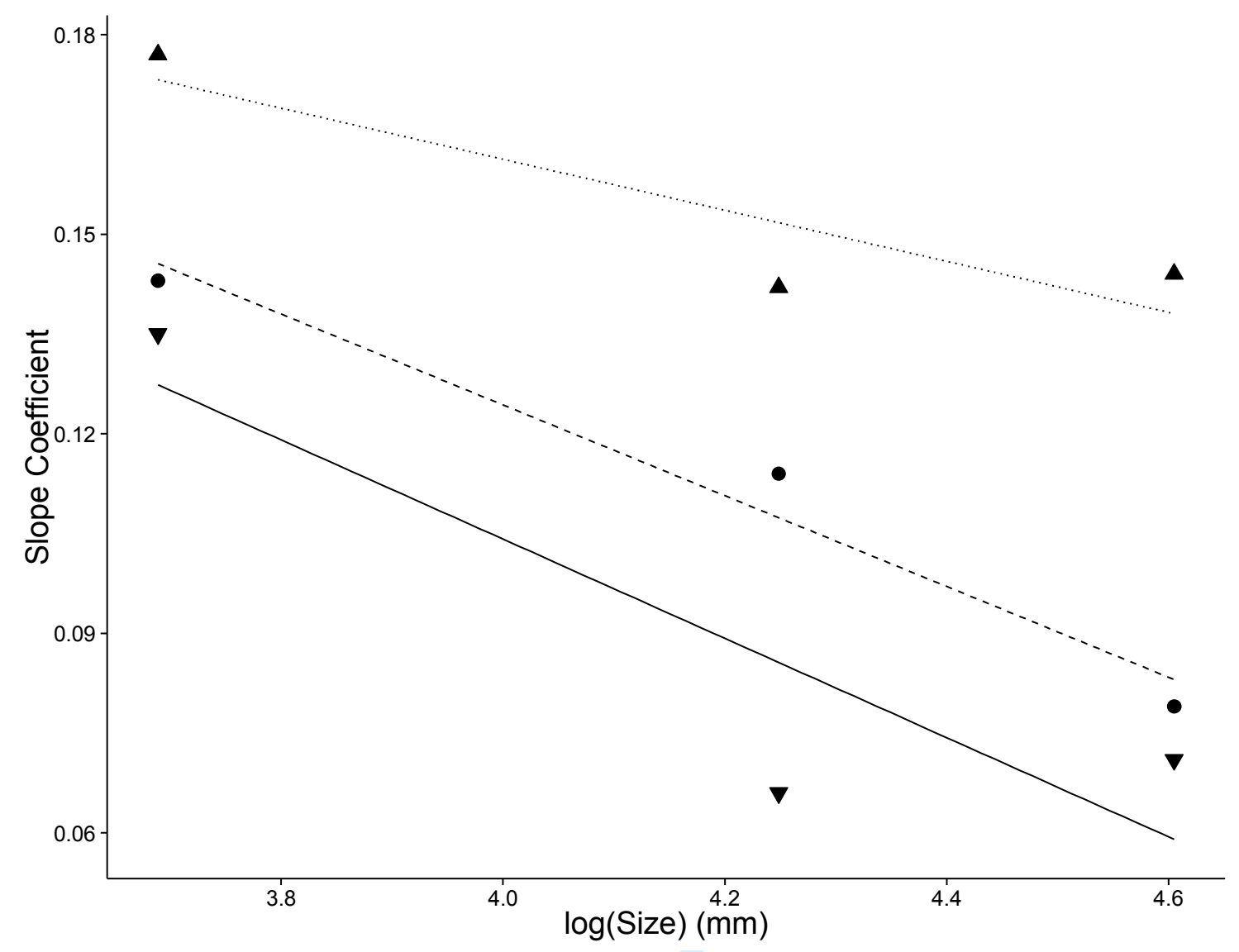

Figure 5. Multiple regression model displaying how the gut evacuation slope coefficients vary with age- 0 pallid sturgeon length ( $\log _{\mathrm{e}}($ length)) and water temperature $\left({ }^{\circ} \mathrm{C}\right)$. Temperatures are indicated by $(-\nabla-)$ for $14^{\circ} \mathrm{C},\left(--\mathbf{-}^{-}\right)$for $18^{\circ} \mathrm{C}$ and $(\cdot \mathbf{\Delta} \cdot \cdot)$ for $24^{\circ} \mathrm{C}$. 

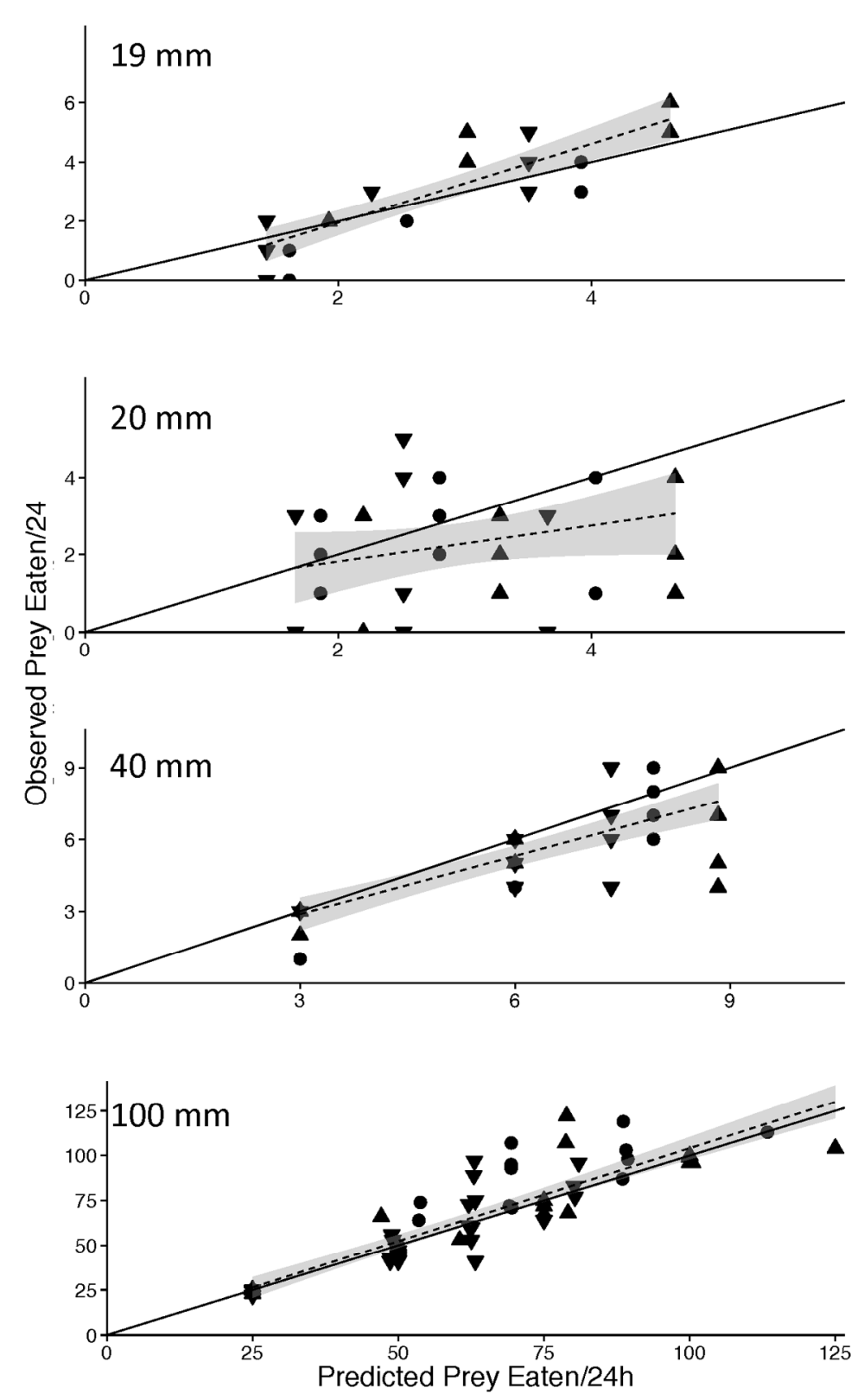

Figure 6. Plots displaying the observed number of prey eaten against the model predictions for the $24 \mathrm{~h}$ feeding trials for each size class. The solid line represents the 1 to 1 line whereas the dashed line represents the fitted regression line through the observed and predicted data. The grey area around the regression line represents the $95 \%$ confidence interval. Temperatures are indicated by ( $\nabla)$ for $14^{\circ} \mathrm{C},(\mathbf{O})$ for $18^{\circ} \mathrm{C}$ and $(\mathbf{A})$ for $24^{\circ} \mathrm{C}$. 

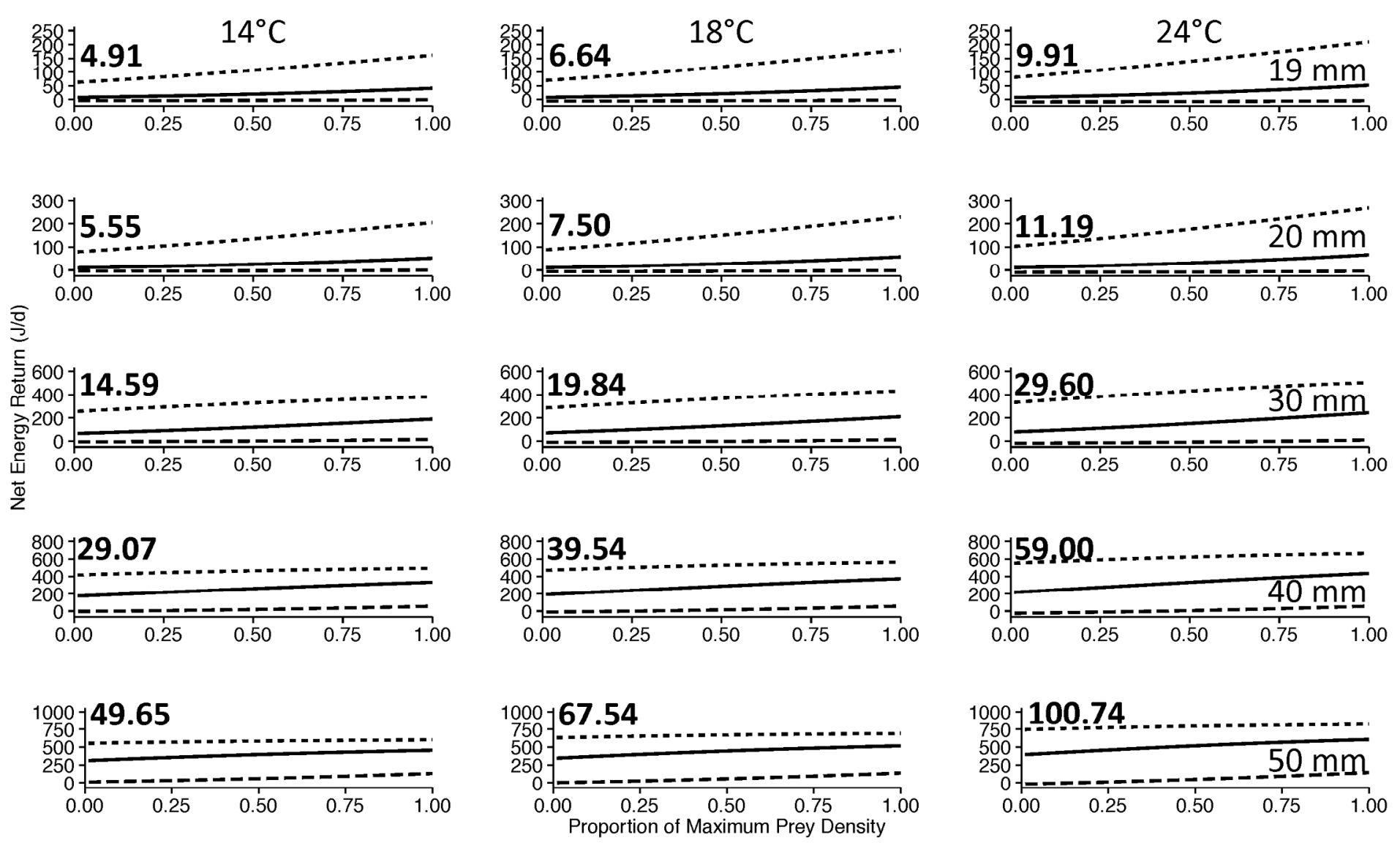

Figure 7. Plots demonstrating the effect of temperature, prey density, prey type and predator size on daily net energy return. The minimum proportion of maximum prey density is set to 0.01 . The number in bold represents the minimum energy needed for the fish to maintain its weight for a day. Fish feeding on zooplankton, Chironomidae or Ephemeroptera larvae, are indicated by $(---),(-)$, or $(\bullet \bullet)$, respectively. 